UNIVERSIDADE DE SÃO PAULO

FACULDADE DE ODONTOLOGIA DE RIBEIRÃO PRETO

\title{
ANÁLISE FOTOELÁSTICA DE TENSÕES TRANSMITIDAS A IMPLANTES CURTOS
}

Janisse Martinelli Borges de Oliveira 


\title{
JANISSE MARTINELLI BORGES DE OLIVEIRA
}

\section{ANÁLISE FOTOELÁSTICA DE TENSÕES TRANSMITIDAS A IMPLANTES CURTOS}

\author{
Tese de Doutorado apresentada ao Curso de Pós-graduação \\ da Faculdade de Odontologia de Ribeirão Preto - USP para \\ obtenção do Título de Doutor em Odontologia \\ Área de Concentração: Reabilitação Oral.
}

Orientadora: Prof ${ }^{a}$. Dr ${ }^{\mathrm{a}}$. Maria da Gloria Chiarello de Mattos

\section{Ribeirão Preto}


Autorizo a reprodução e a divulgação total ou parcial deste trabalho, por qualquer meio convencional ou eletrônico para fins de estudo e pesquisa, desde que citada a fonte.

\section{FICHA CATALOGRÁFICA}

Martinelli, Janisse

Análise fotoelástica de tensões transmitidas a implantes curtos.

82 p. : il.; $30 \mathrm{~cm}$

Tese de Doutorado, apresentada à Faculdade de Odontologia de Ribeirão Preto/ Universidade de São Paulo - USP. Área de concentração: Reabilitação Oral.

Orientadora: Mattos, Maria da Glória Chiarello de

1. Implantes Osseointegrados. 2. Implantes Curtos. 3. Fotoelasticidade 


\section{FOLHA DE APROVAÇÃO}

Janisse Martinelli Borges de Oliveira

Análise fotoelástica de tensões transmitidas a implantes curtos.

Tese apresentada à Comissão de Pós-Graduação da área de Reabilitação Oral da Faculdade de Odontologia de Ribeirão Preto da Universidade de São Paulo para obtenção de título de Doutor em Odontologia.

Ribeirão Preto,

\section{Banca Examinadora}

Prof (a). Dr (a).:

Instituição: Assinatura:

Prof (a). Dr (a).:

Instituição: Assinatura:

Prof (a). Dr (a).:

Instituição: Assinatura:

Prof (a). Dr (a).:

Instituição: Assinatura:

Prof (a). Dr (a).: 
“Há dois tipos de sabedoria:

a inferior e a superior.

A sabedoria inferior é dada pelo quanto uma pessoa sabe E a superior é dada pelo quanto ela tem consciência de que não sabe.

Tenha a sabedoria superior.

Seja um eterno aprendiz na escola da vida.

A sabedoria superior tolera;

a inferior, julga;

a superior, alivia;

a inferior, culpa;

a superior, perdoa;

a inferior, condena.

Tem coisas que o coração só fala para quem sabe escutar!" 
DEDICO ESTE TRABALHO:

Aos meus pais Wildomar e Gislene,

Vocês são meus mais queridos professores! Agradeço da mamãe a doçura e a serenidade, E do papai o carinho e a segurança Nos momentos mais difíceis. A vocês minha eterna gratidão e todo meu amor!

Aos meus irmãos Anelise e Lucius, A quem tanto amo, a quem desejo toda a felicidade do mundo!

Ao meu querido Felipe, O maior companheiro que poderia querer...

L'amore de tutte le mie vite! 
AGRADECIMENTO ESPECIAL

À Prof ${ }^{a}$. Dr ${ }^{a}$. Maria da Gloria Chiarello de Mattos, o meu sincero muito obrigada. Agradeço o carinho e a generosidade em tantos momentos... Agradeço por ter tido você tão próxima durante esses 5 anos. Pessoa inesquecível, coração inesquecível, risada inesquecível. Sabedoria a ser seguida. 


\section{AGRADECIMENTOS}

À Faculdade de Odontologia de Ribeirão Preto da Universidade de São Paulo, pela formação brilhante que proporciona a seus alunos, agradeço imensamente a acolhida durante esses 10 anos que compreendem meus cursos de graduação e pós-graduação.

Ao Departamento de Materiais Dentários e Prótese, na pessoa da Prof. ${ }^{a}$ Dr $^{a}$. Helena de Oliveira Paranhos, Chefe de Departamento por disponibilizar diferentes laboratórios para que fosse possível o desenvolvimento dessa Tese de Doutorado, e também na pessoa da Prof. ${ }^{a}$ Dr $^{a}$. Fernanda de Carvalho Panzeri Pires de Souza, Coordenadora da Pós Graduação da área de Reabilitação Oral, pelo carinho e respeito que sempre teve comigo, desde a época da Iniciação Científica.

Aos Prof. Dr. Ricardo Faria Ribeiro e Prof $f^{a}$. Dra. Renata Cristina Silveira Rodrigues Ferracioli por tantos ensinamentos generosamente compartilhados.

À Msa. Ana Paula Macedo, minha orientadora do coração, que mais uma vez se fez imprescindível no desenvolvimento dessa tese. Agradeço a amizade e paciência.

À Dr $^{a}$. Adriana Claudia Lapria Faria Queiroz, por toda ajuda e pela serenidade que tanto me tranqüilizava nos momentos difíceis.

Ao Dr. Rodrigo Tiossi, grande pesquisador que generosamente tanto me auxiliou durante várias etapas da minha tese.

Aos funcionários Regiane de Cássia Tirado Damasceno, Isabel Cristina Galino Sola, Regiane Cristina Moi Sacilotto, Ana Paula Xavier, Fernanda Talita de Freitas, Luis Sérgio Soares, Paulo Sérgio Ferreira, Lício Firmino Junior, Paulo Donato Frigheto, Marcelo Aparecido Vieira, Fernando Schiavetto, Eduardo Destito, Odair Rosa Silva, José de Godoi Filho, que de uma maneira ou de outra foram tão importantes na minha formação, ao longo de todos esses anos.

Aos amigos da pós-graduação, do Mestrado e Doutorado. Espero encontrá-los lecionando e pesquisando por esse Brasil a fora!

Ao Laboratório de Prótese Dentária Rui de Castro Ballego localizado em Uberaba - MG, nas pessoas de Neide, Cássia, Karina e Rodrigo, que se fizeram imprescindíveis na confecção das próteses e prensagem da cerâmica, e em especial ao Rui de Castro Ballego que cedeu seu tempo aos meus questionamentos e sempre, de maneira gentil e com competência inquestionável tanto me ensinou sobre as propriedades das cerâmicas. É de profissionais generosos como você que o meio científico precisa. 
Este trabalho foi realizado no Laboratório de Estudos Biomecânicos em Prótese e Implantes do Departamento de Materiais Dentários e Prótese da Faculdade de Odontologia de Ribeirão Preto da Universidade de São Paulo. 
Martinelli, J. Análise fotoelástica de tensões transmitidas a implantes curtos. 2011. 82 p. Tese (Doutorado) - Faculdade de Odontologia de Ribeirão Preto, Universidade de São Paulo, Ribeirão Preto.

\section{RESUMO}

O objetivo desse trabalho foi avaliar, pelo método fotoelástico, de que maneira cargas aplicadas sobre próteses metalocerâmicas implantossuportadas eram transmitidas a implantes de diferentes comprimentos, e como a proporção coroa/implante influenciaria essa distribuição de tensões. A partir de quatro modelos mestres em resina do tipo policarbonato foram confeccionados quatro modelos em resina fotoelástica (Araldite) simulando extremidade livre mandibular, com o dente 44 em resina (Luxatemp) e os dentes 45, 46 e 47 substituídos por implantes com $4 \mathrm{~mm}$ de diâmetro. O grupo 1 (G1) foi formado por 2 implantes de comprimento convencional ou longo (11 mm; Titamax Cortical CM, Neodent) substituindo o 45 e o 46, e 1 implante curto (5 mm; Ws Cortical CM, Neodent) substituindo o 47. O grupo 2 (G2) apresentava 1 implante com $11 \mathrm{~mm}$ (45) e 2 implantes com 5 mm (46 e 47). O grupo 3 (G3) foi reabilitado por 3 implantes de 5 mm e o grupo 4 (G4) por 3 implantes de $11 \mathrm{~mm}$ de comprimento. Nos grupos com implantes de $5 \mathrm{~mm}$ foi simulada reabsorção óssea de $4 \mathrm{~mm}$ de altura. Coroas metalocerâmicas unidas foram parafusadas sobre os minipilares intermediários. Foram realizados diferentes carregamentos oclusais sobre as coroas: oclusal balanceado de $150 \mathrm{~N}$, puntiforme de $100 \mathrm{~N}$ na mesial do 45 e puntiforme de $100 \mathrm{~N}$ na distal do 47. Análise fotoelástica quantitativa determinou a tensão transmitida (MPa) nos grupos: G1 (84.73), G2 (136.36), G3 (126.77) e G4 (164.72) para a carga oclusal balanceada; G1 (91.66), G2 (70.93), G3 (93.08) e G4 (119.82) para a carga na mesial do 45; e G1 (75.22), G2 (70.88), G3 (93.79) e G4 (117.56) para a carga na distal do 47. Para os implantes curtos, em todos os casos, a proporção coroa/implante foi maior que 2,5 e para os implantes de comprimento convencional essa proporção foi 1, em média. Após as análises realizadas, foi possível concluir que os maiores valores de tensões foram encontrados no grupo com 3 implantes longos (G4), e o aumento da proporção coroa/implante não mostrou correlação com maior concentração de tensões. Comparativamente, a utilização de implantes curtos reduziu as tensões transmitidas ao redor dos implantes. 
Martinelli, J. Photoelastic analysis of tensions transmitted to short implants. 2011. 82 p. Tese (Doutorado) - Faculdade de Odontologia de Ribeirão Preto, Universidade de São Paulo, Ribeirão Preto.

\begin{abstract}
The aim of this study was to evaluate by the photoelastic method, stress transmission to implants of different lengths by metal-ceramic crowns under different loads, and how crown/implant ratio influenced this stress distribution. From four matrixes, four photoelastic models (Araldite) were made simulating free mandibular end, with teeth 44 in resin (Luxatemp) and tooth 45, 46 and 47 replaced by implants with $4 \mathrm{~mm}$ in diameter. Group 1 (G1) was formed by two implants with conventional length or long (11 mm; Titamax Cortical CM, Neodent) replacing tooth 45 and 46, and one short implant (5 mm; Ws Cortical CM, Neodent) replacing the 47. Group 2 (G2) had one implant with $11 \mathrm{~mm}$ (45) and 2 implants with $5 \mathrm{~mm}$ (46 and 47). Group 3 (G3) was rehabilitated by three implants of $5 \mathrm{~mm}$ and group 4 (G4) for 3 implants of $11 \mathrm{~mm}$ in length. In the groups with $5 \mathrm{~mm}$ implants was simulated 4 mm bone resorption in height. Metal-ceramic fixed prosthesis was bolted on the abutments. Different oclusal loads were performed over the crowns, $150 \mathrm{~N}$ in occlusal balanced, $100 \mathrm{~N}$ on the 45 mesial, and $100 \mathrm{~N}$ on the 47 distal. Quantitatively photoelastic analysis determined the stress transmitted (MPa) on the groups: G1 (84.73), G2 (136.36), G3 (126.77) and G4 (164.72) for the occlusal load balanced, G1 (91.66), G2 (70.93), G3 (93.08) and G4 (119.82) for charging on the 45 mesial, and G1 (75.22), G2 (70.88), G3 (93.79) and G4 (117.56) to the load on the 47 distal. Crown/implant ratio for short implants was greater than 2.5 and for long implants was about 1 . After analysis, it was concluded that the highest values of strains were found in the group with three long implants (G4), and the increased crown/implant ratio showed no correlation with the highest stress concentration. Comparatively, the use of short implants reduced stress around the implants.
\end{abstract}




\section{SUMÁRIO}

\section{RESUMO}

\section{ABSTRACT}

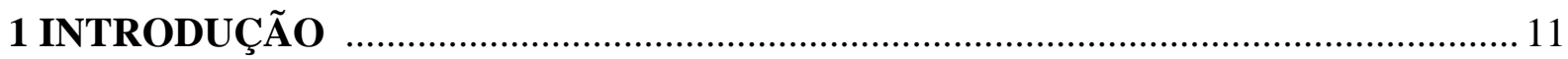

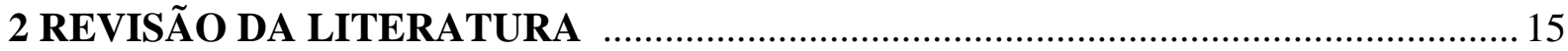

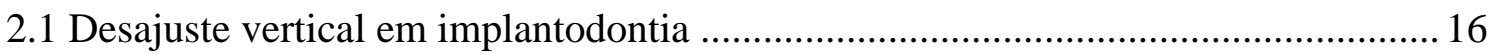

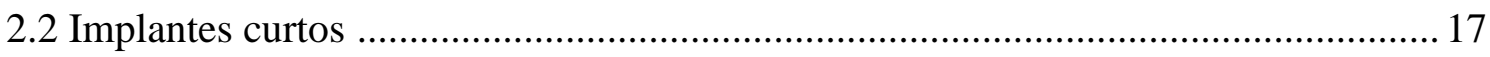

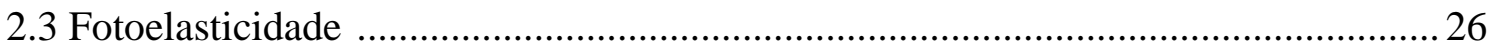

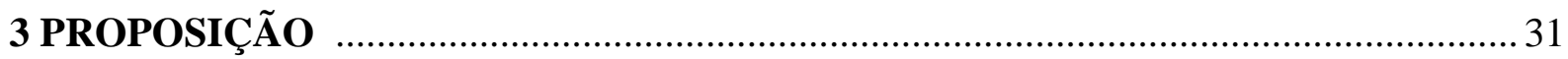

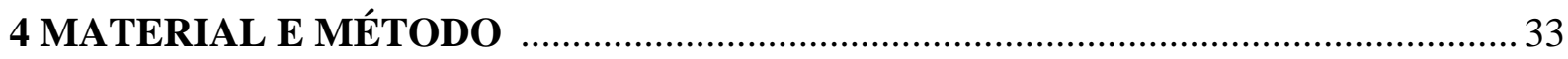

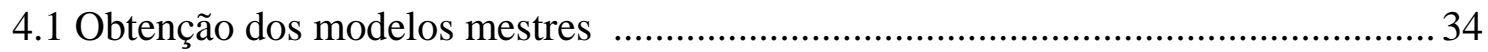

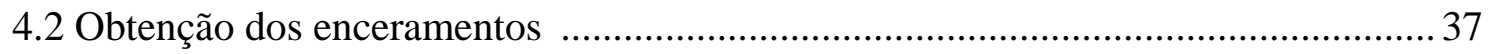

4.3 Inclusão, fundição e soldagem à laser das estruturas metálicas ............................. 40

4.4 Aplicação do opaco e prensagem da cerâmica ........................................................ 43

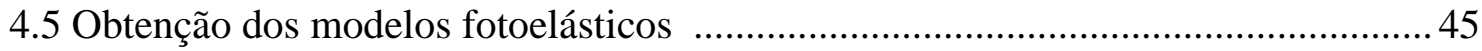

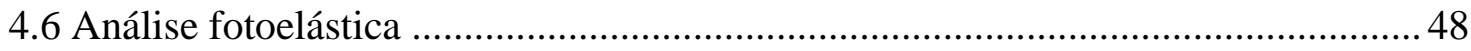

4.7 Análise da proporção coroa/implante .............................................................. 54

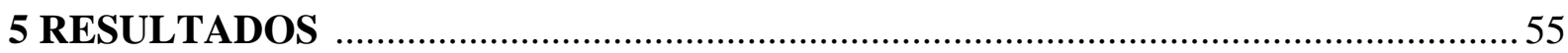

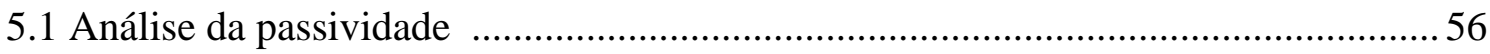

5.2 Análise fotoelástica qualitativa e quantitativa ........................................................ 57

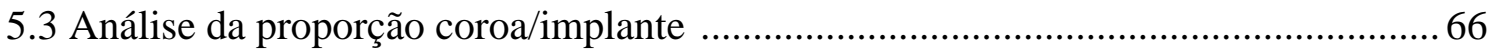

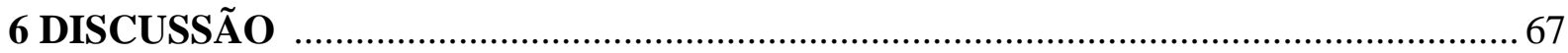

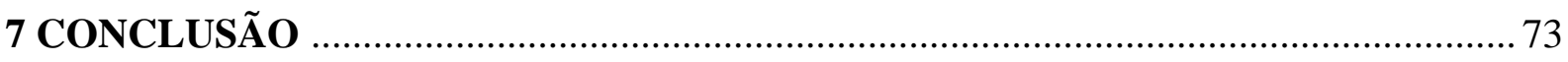

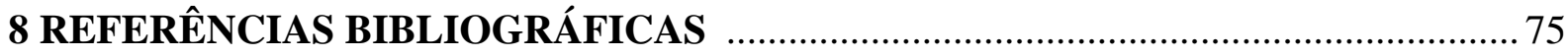


INTRODUÇÃO 


\section{INTRODUÇÃO}

A utilização de implantes dentários é hoje, na maioria das vezes, o modo escolhido para tratamento de pacientes desdentados parciais (MISCH et al. 2006). Uma definição de osseointegração (termo originalmente proposto por Branemark et al., 1969) estabelecida por Albrektsson e Linder (1981) seria “uma conecção direta entre osso vivo e a superfície de um implante submetido à carga funcional”. Após diferentes estudos de microscopia eletrônica, a osseointegração foi redefinida como “o processo pelo qual uma fixação rígida e clinicamente assintomática de um material aloplástico é alcançada e mantida em contato ósseo durante as cargas funcionais (ZARB; ALBREKTSSON, 1991).

Contudo, o comportamento biomecânico de implantes osseointegrados e dentes naturais é diferente. Dentes naturais possuem ligamento periodontal, o que lhes propicia mobilidade de aproximadamente $100 \mu \mathrm{m}$, permitindo acomodação de próteses fixas com certo grau de desajuste, sem causar danos ao tecido ósseo (WATANABE et al., 2000). Implantes osseointegrados, por sua vez, apresentam mobilidade dez vezes menor, cerca de $10 \mu \mathrm{m}$, valor atribuído à elasticidade óssea (WATANABE et al., 2000). Assim, cargas excessivas geradas aos implantes podem transmitir tensões nocivas que ultrapassem a capacidade elástica do osso, levando à reabsorção óssea perimplantar (RIEDY et al., 1997).

A reabsorção óssea, uma das principais complicações que ocorrem no tratamento com implantes osseointegrados, se inicia primeiramente ao nível da crista óssea marginal, como resultado de incidência de tensões nocivas geradas ao implantes (GOODACRE et al., 2003, BLANES et al., 2007). Após o primeiro ano de instalação, a média de reabsorção óssea perimplantar é de 0,9 mm, e nos anos subseqüentes a média cai para 0,1 mm a cada ano (GOODACRE et al., 2003). 
Vários pesquisadores enumeraram fatores que podem influenciar de maneira significativa a perda óssea marginal, como por exemplo: a configuração protética, a proporção coroa/implante, o desajuste cervical da prótese, número e distribuição dos implantes na área desdentada, oclusão e comprimento do implante (RANGERT et al., 1995; CARR et al., 1996; PAPAVASILIOU et al., 1996; GOODACRE et al., 2003; MISCH, et al., 2006; NEVES et al. 2006; ANITUA, ORIVE, 2010).

A ferulização de próteses sobre implantes é recomendada por promover melhor distribuição das forças oclusais antagonistas (MISCH et al., 2006; TIOSSI et al., 2011), reduzindo as tensões transmitidas ao tecido ósseo. Já a sobrecarga oclusal pode causar reabsorção óssea e possível fratura do implante ou do parafuso do intermediário, especialmente na região de primeiro molar inferior (RANGERT et al., 1995).

Regiões desdentadas posteriores tanto na mandíbula quanto na maxila freqüentemente apresentam menor altura óssea devido à proximidade ao nervo alveolar inferior e ao assoalho do seio maxilar, respectivamente, muitas vezes com espaço inferior a $10 \mathrm{~mm}$ para instalação de implantes (MISCH et al., 2006). Métodos para aumentar a altura óssea nessas regiões como enxerto autógeno e lateralização do nervo alveolar inferior têm revelado altos índices de morbidade, além de resultar em aumento de custos ao paciente e elevar o tempo de tratamento (NEVES et al., 2006). Uma opção conservadora seria a utilização de implantes curtos, contudo a literatura científica é bastante controversa em relação a sua eficiência, sendo possível encontrar autores que relatam falha desses implantes (FRIBERG et al., 1991; JEMT, LEKHOLM, 1993; BAHAT, 2000), e mais recentemente, outros que asseguram sua longevidade clínica (MISCH et al., 2006; TAWIL et al., 2006; NEVES et al., 2006; DEGIDI et al., 2007; GRANT et al., 2009).

Assim como não há concordância acerca de qual seria o comprimento ideal de implantes, o planejamento protético também não é consenso científico. Vários trabalhos 
procuram a melhor configuração protética para reabilitações sobre implantes, especialmente na tentativa de minimizar tensões excessivas transmitidas ao tecido ósseo adjacente. Diferentes metodologias têm sido utilizadas em estudos de análise de tensões transmitidas à região perimplantar como a fotoelasticidade, a extensiometria, análise de elementos finitos e a correlação de imagens (CLELLAND et al., 1993; GUICHET et al., 2000; GUICHET et al., 2002; PIERRISNARD et al., 2003; MENANI et al., 2011; TIOSSI et al., 2011).

A fotoelasticidade é uma técnica utilizada no estudo da distribuição de tensões geradas ao redor dos implantes desde a década de 1980 (HARALDSON, 1980). Quando determinada carga é aplicada a uma resina com propriedade fotoelástica, ocorre alteração do seu padrão refrativo, e com auxílio de um polariscópio é possível visualizar alterações de sua coloração (MENANI et al., 2011). Sendo assim, diferentes situações podem ser comparadas pela maneira como as cores se distribuem na resina fotoelástica (MENANI et al., 2011). Esse método é amplamente utilizado na odontologia porque, embora sejam diferentes os módulos de elasticidade do tecido ósseo e da resina fotoelástica, o padrão de concentração e distribuição de tensões é semelhante (AKÇA et al., 2008). 
REVISÃO DE LITERATURA 


\section{REVISÃO DA LITERATURA}

\subsection{Desajuste vertical em implantodontia}

Em 1994, Aparício relata que a passividade da prótese é vital para a manutenção da osseointegração. A ausência de ligamento periodontal nos implantes osseointegrados não permite que ocorram micro movimentações, o que os torna incapazes de se adequarem aos desajustes protéticos. Assim, qualquer desajuste, por menor que seja, acaba gerando tensões na interface osso-implante. O autor salienta que a adaptação passiva é caracterizada pela existência de contato circunferencial simultâneo de toda superfície de assentamento da prótese com os pilares de suporte e, clinicamente, pode ser avaliada de acordo com alguns parâmetros: ausência de sensação de tensão ou dor durante a instalação da estrutura sobre os implantes; aperto final de todos os parafusos protéticos realizando não mais do que 1/3 de volta; controle visual com auxílio de lupa para as margens supra gengivais; controle radiográfico do ajuste da estrutura a cada um dos pilares com apenas um dos parafusos distais apertados.

Sahin e Çehreli (2001) estudaram o efeito da falta de passividade encontrada na confecção de próteses sobre implantes. Os autores relataram que a passividade absoluta não pode ser alcançada, e que a quantidade de estudos longitudinais que sobre falhas especificamente atribuídas à desadaptação da peça protética é bastante escassa. Ainda, os autores colocaram em discussão se realmente é importante a busca por uma adaptação absoluta entre os intermediários e as próteses, e questionaram qual seria a adaptação aceitável.

Karl et al. (2006), realizaram um trabalho que teve por objetivo determinar a tensão transmitida por uma prótese parcial fixa suportada por implantes, utilizando a técnica do strain gauge, in vivo. Foram confeccionados quatro tipos de próteses parciais fixas: o grupo 1 
era composto por próteses cimentadas, moldadas pela técnica de reposicionamento e fundidas com copings calcináveis; no grupo 2 as próteses parafusadas foram moldadas pela técnica de arrasto usando copings calcináveis; no grupo 3, próteses parafusadas foram moldadas pela técnica de arrasto e sobre-fundidas em cilindros de ouro e, para o grupo 4, próteses parafusadas foram moldadas pela técnica de arrasto unidas aos cilindros de ouro. As medições do strain gauge foram obtidas durante a cimentação e o aperto dos parafusos. Os resultados mostraram a presença de tensões para as próteses cimentadas, parafusadas, e também para as próteses unidas aos cilindros de ouro.

Goodacre et al. (2003) analisaram artigos científicos publicados no período de 1981 a 2001 que relatavam complicações ocorridas com implantes osseointegrados e próteses sobre implantes. Após as análises, os autores encontraram 14 diferentes tipos de complicações que se relacionavam a falhas mecânicas. Dessas falhas, 30\% correspondiam à perda de retenção de sobredentaduras, $1 \%$ era para fratura de implantes, onde $7 \%$ relataram afrouxamento do parafuso protético, 6\% afrouxamento do parafuso do intermediário, 4\% fratura do parafuso protético, 3\% fratura da infraestrutura e 2\% fratura do parafuso do intermediário.

\subsection{Implantes Curtos}

Bruggenkate et al. (1998) realizaram um estudo multicêntrico de implantes curtos ITI, com a finalidade de verificar seus resultados clínicos. Durante o período de 6 anos, 253 implantes com comprimento de $6 \mathrm{~mm}$ foram instalados em 126 pacientes, seguidos pelo período de 1 a 7 anos. Segundo os autores, 7 implantes foram removidos no total, 6 localizados na maxila e 1 na mandíbula. Os resultados clínicos mostraram semelhança entre a longevidade dos implantes curtos e longos quando utilizado esse sistema de implantes. Embora os resultados clínicos com implantes curtos sejam favoráveis, os autores 
recomendam, contudo, que sejam utilizados associados a implantes longos, especialmente quando instalados em osso menos denso, o que ocorre com freqüência na maxila.

Tawil e Younan (2003) avaliaram o sucesso clínico de implantes curtos com superfície lisa instalados em maxila e mandíbula. Duzentos e sessenta e nove implantes foram instalados em 111 pacientes. Na mandíbula foram perdidos 10 implantes e na maxila apenas 2, sendo que 11 implantes foram instalados na região de molares e 1 na região de pré-molar. Ao final da análise, os autores concluíram que implantes curtos lisos podem ser instalados com sucesso em regiões com pouca altura óssea.

Ainda em 2003, Pierrisnard et al. publicaram interessante estudo no qual avaliaram, pelo método de elementos finitos, de que maneira o comprimento e a ancoragem bicortical influenciam a transferência de tensões aos componentes protéticos, ao tecido ósseo adjacente e ao implante propriamente dito. Foi confeccionado um modelo tridimensional, com implantes de 3,75 mm de diâmetro, com comprimentos de 6, 7, 8, 9, 10, 11 e 12 mm. Cada implante foi modelado com intermediário e parafuso de titânio, cilindro de ouro e prótese metalocerâmica parafusada. Foi simulado o posicionamento dos implantes de maneira que houvesse osso cortical e medular envolvendo-os. Foi aplicada carga oclusal de $100 \mathrm{~N}$ com inclinação de $30^{\circ}$ em relação ao longo eixo dos implantes. Ao final da simulação, os autores observaram que a tensão transmitida ao tecido ósseo foi praticamente constante, independente o comprimento e da ancoragem bicortical dos implantes. Contudo, os maiores valores de tensões nos implantes foram associados ao aumento dos comprimentos dos implantes e à ancoragem bicortical.

Em 2005, Renouard e Nisand publicaram um estudo retrospectivo de 2 anos avaliando o sucesso de implantes curtos instalados em maxila severamente reabsorvidas. Foram instalados 96 implantes curtos (6, 7 e $8,5 \mathrm{~mm}$ de comprimento) em 85 pacientes, que receberam próteses unitárias ou próteses ferulizadas. Desse total, 54 dos implantes possuíam 
superfície lisa e 42 superfícies tratadas. Foram realizadas cirurgias em passo único, com instalação do intermediário protético durante a cirurgia. Os pacientes foram avaliados por pelo menos 2 anos sendo a perda óssea marginal documentada por análises radiográficas. Os autores observaram que 5 implantes falharam nos primeiros 9 meses, sendo que 4 apresentavam superfície lisa e apenas 1 apresentava superfície tratada. Além disso, a perda óssea marginal média, após a prótese estar em função pelo período de 2 anos foi de $0,44 \pm 0,52$ mm. Ao final desse estudo clínico retrospectivo, os autores concluíram que o uso de implantes curtos deve ser considerado para reabilitações protéticas de maxilas severamente reabsorvidas com alternativa segura a técnicas cirúrgicas mais complicadas.

Romeo et al. (2005) avaliaram clinicamente implantes de diferentes comprimentos (8 e $10 \mathrm{~mm}$ ) e diâmetros (3,75; 4,1 e 4,8 mm), com acompanhamento de 14 anos. No total, 129 pacientes receberam próteses fixas implantossuportadas (unitárias ou múltiplas; cimentadas ou parafusadas) por 154 implantes com 10 mm de comprimento (convencional), e 111 com 8 mm (curto). Ainda, 141 implantes apresentavam superfície tratada com spray de plasma e 124 com superfície do tipo SLA. Após o período de 14 anos, foram perdidos oito implantes instalados em osso tipo 3 e 4, sendo que metade apresentava comprimento curto. Os autores avaliaram também a retração gengival e a perda óssea perimplantar, não encontrando influencia do comprimento ou do diâmetro dos implantes nessas perdas. O sucesso clínico desse estudo, após o período de 14 anos foi de 97,9\% e 97,1\% para implantes curtos e de comprimento convencional, respectivamente. Quanto ao tratamento de superfície, houve sucesso de 92,3\% e 95,9\% respectivamente, para implantes curtos e convencionais com superfície tratada por spray de plasma; e 100\% e 98,5\% respectivamente, para implantes curtos e convencionais com superfície tratada por SLA. Os autores concluíram que não houve influência do comprimento, diâmetro e tratamento de superfície na longevidade do tratamento reabilitador utilizando implantes osseointegrados. 
Ainda em 2005, Goene e equipe realizaram um estudo pelo período de 3 anos em que avaliaram o sucesso de implantes de diferentes comprimentos. Nesse estudo foram avaliados 311 implantes com superfície tratada, de 7 e 8,5 mm de comprimento, instalados a maioria em regiões com tecido ósseo de baixa qualidade. Durante esse período de avaliação, 13 implantes falharam, sendo que 9 dessas falhas ocorreram antes da instalação da prótese e os 4 restantes aconteceram em pacientes fumantes. Os autores concluíram que implantes curtos podem ser utilizados em áreas posteriores com segurança.

Neves et al. (2006) analisaram, por meio de metanálise, a utilização e o sucesso clínico de implantes curtos. Foram incluídos no estudo artigos publicados entre 1980 e 2004. Os critérios para inclusão dos artigos no estudo foram: o número de implantes com comprimentos de 7, 8.5 e $10 \mathrm{~mm}$ colocados e perdidos, quando a falha ocorreu e os fatores de risco relatados em 33 trabalhos. Os estudos mostraram que dos 16.344 implantes que foram instalados, 786 (4,8\%) falharam, sendo que 9,7\% dos implantes com 3,75 mm de diâmetro e 7 mm de comprimento falharam, enquanto que implantes de mesmo diâmetro e comprimento de $10 \mathrm{~mm}$ tiveram 6,3\% de falha. Foi encontrado que 54,9\% das falhas ocorreram antes da colocação dos componentes protéticos. Os autores observaram também que 66,7\% das falhas foram atribuídas à pobre qualidade óssea, 45,5\% à localização (maxila ou mandíbula), 27,2\% à sobrecarga oclusal, 24,2\% à localização ao longo da mandíbula, e 15,1\% a infecções. A análise revelou que entre os fatores de risco, a pobre qualidade óssea associada a implantes curtos parece ser relevante para que a falha ocorra. A utilização de implantes de $4 \mathrm{~mm}$ de diâmetro minimizou as falhas, e os implantes que possuíam 3,75 mm de diâmetro e 7 mm de comprimento apresentaram a maior porcentagem de falha $(9,7 \%$ dos 1.894 implantes analisados). Os autores, ao final dessa revisão sistemática de artigos, concluíram que implantes curtos podem ser considerados uma alternativa a cirurgias de enxerto ósseo, desde que essas cirurgias envolvam alto risco de morbidade e alto custo aos pacientes. 
Ainda em 2006, Tawil et al., realizaram um estudo com o objetivo de determinar a influência de alguns fatores protéticos envolvidos na longevidade e também nas complicações dos implantes. Para tanto, 262 implantes foram instalados em 109 pacientes que foram acompanhados pelo tempo médio de 53 meses. Foi analisada de que maneira parâmetros protéticos influenciam a perda óssea perimplantar, complicações biológicas e biomecânicas. A relação entre a coroa e a parte osseointegrada do implante observada nesse estudo foi relativamente pequena (entre 1 e 2) e a mesa oclusal variou de 5,4 a 8,3 mm. A dentição oposta era em sua maioria a dentição natural, prótese parcial fixa, ou restauração fixa implantossuportada. A oclusão com relação maxilomandibular normal foi encontrada em 72,7\% dos casos. Não foi encontrada diferença significante na perda óssea perimplantar correlacionada com a proporção coroa/implante, mesa oclusal, comprimento do cantilever ou bruxismo, sendo que a perda óssea média foi de 0,74 $\pm 0,65 \mathrm{~mm}$. Segundo os autores, o aumento dos valores de proporção tanto da coroa/implante quanto da mesa oclusal parece não ser o maior fator de risco em casos onde a carga oclusal é favorável. Em 67\% dos casos, o comprimento mésio-distal das próteses foi menor que o comprimento da dentição natural correspondente, o que pode haver contribuído para a melhor distribuição de cargas e obtenção de resultados favoráveis. Ao final do estudo os autores concluíram que implantes curtos tendem a ser uma solução satisfatória de longo prazo em regiões onde há reduzida altura óssea, até mesmo quando os parâmetros protéticos excedem valores tidos como normais, evidenciando que tanto a orientação das forças oclusais quanto a distribuição de cargas são importantes, desde que os inconvenientes de para-funções controlados.

Misch e equipe, no mesmo ano, publicaram um estudo retrospectivo em que avaliaram implantes curtos pelo período de seis anos. Nesse trabalho 273 pacientes receberam 745 implantes de 7 ou 9 mm de comprimento, reabilitados por 338 restaurações protéticas. Para evitar que tensões excessivas fossem transmitidas aos implantes posteriores, foram 
confeccionadas próteses ferulizadas, sem a presença de cantilever, com guia de desoclusão ou mutuamente protegida ou guia canina, e implantes com tratamento de superfície que aumentasse o contato osso/implante. Como resultado, os autores observaram 6 falhas na osseointegração antes da cirurgia de reabertura e 2 falhas entre o período da reabertura e da instalação da prótese. O interessante é que nesse estudo, nenhuma falha foi observada após a instalação das próteses. Os pesquisadores concluem que implantes curtos podem ser utilizados com segurança em reabilitações protéticas de áreas edêntulas posteriores. Ressaltam que métodos que diminuam o estresse biomecânico à interface osso/implante são importantes para garantir o sucesso do tratamento.

Arlin em 2006 realizou um estudo com o objetivo de avaliar a longevidade de implantes curtos de 6 e 8 mm de comprimento instalados em áreas de reduzida altura óssea (7 e $11 \mathrm{~mm})$, comparando-os a implantes longos. Foram instalados 623 implantes em 264 pacientes durante o período de 12 anos, sendo que 35 implantes tinham $6 \mathrm{~mm}$ de comprimento, 141 tinham $8 \mathrm{~mm}$ e 454 tinham entre 10 e $16 \mathrm{~mm}$ de comprimento. O tempo máximo de acompanhamento desses implantes foi de 64,6 meses para os de 6 mm; 83,7 meses para os de 8 mm, e 102 meses para os implantes com comprimento entre 10 e 16 mm. Segundo o autor, a porcentagem de sucesso dos implantes para o período de 2 anos foi de, respectivamente 94,3\%, 99,3\% e 97,4\% para os implantes de $6 \mathrm{~mm}, 8 \mathrm{~mm}$ e 10-16 mm, indicando que a taxa de sucesso de implantes curtos (6 e $8 \mathrm{~mm}$ ) foi semelhante àquela encontrada para implantes longos (10-16 mm), por esse período de tempo. Nesse estudo, o autor concluiu que os implantes curtos representaram boa alternativa para a reabilitação oclusal de pacientes com pouca altura óssea, sem a necessidade de realização de enxertos ósseos, mostrando que, pelo período de 2 anos, os implantes curtos revelaram sobrevida semelhante aos longos. 
No ano seguinte, Maló e colaboradores avaliaram o sucesso clínico de implantes curtos instalados tanto em maxilas quanto em mandíbulas atróficas. Implantes de 7,0 e 8,5 mm de comprimento foram instalados em 237 pacientes, totalizando 408 implantes. Os intermediários foram instalados no momento da cirurgia de colocação dos implantes e as próteses foram confeccionadas após o período de 4 a 6 meses de osseointegração. No total, os autores observaram que 5 implantes com 7,0 mm de comprimento e 8 com 8,5 mm comprimento falharam antes da instalação das próteses, sendo que todos esses não possuíam tratamento de superfície, e sim superfície lisa. A perda óssea no primeiro ano após a colocação dos implantes foi de $1 \mathrm{~mm}$ para os implantes com 7,0 mm de comprimento e 1,3 mm para os implantes de 8,5 mm. Após 5 anos de segmento clínico, os valores de reabsorção aumentaram respectivamente, para os implantes de 7,0 e $8,5 \mathrm{~mm}$, para 1,8 e 2,2 mm, não excedendo os 0,2 mm por ano (que os autores ressaltam como sucesso clínico). Os pesquisadores concluíram que após 5 anos de acompanhamento clínico, a taxa de sucesso foi de $96,2 \%$ e $97,1 \%$ para os implantes de 7,0 e $8,5 \mathrm{~mm}$ de comprimento, respectivamente. Reforçam ainda que implantes curtos do tipo Branemark podem ser instalados em etapa cirúrgica única com sucesso.

Ainda em 2007, Degidi et al. publicaram um estudo em que avaliaram o sucesso clínico de diferentes tipos/marcas de implantes curtos, com comprimentos menores que 10 $\mathrm{mm}$, que receberam carga imediata. Os autores acompanharam clinicamente por 4 anos, 133 implantes que receberam carga imediata. Ao longo desse período os pesquisadores observaram que apenas 3 implantes falharam, e também que implantes com plataformas menores que 3,75 mm e comprimentos inferiores a $10 \mathrm{~mm}$ proporcionaram perdas ósseas marginais menores, quando comparados com implantes de dimensões maiores. O grupo de pesquisadores concluiu que carga imediata pode ser realizada com sucesso, mesmo quando são utilizados implantes curtos. 
Blanes et al. (2007) avaliaram a influência da proporção coroa/implante e diferentes parâmetros protéticos na reabsorção óssea cervical de implantes instalados na região posterior dos arcos dentários. No total, 192 implantes foram instalados substituindo pré-molares e molares de 83 pacientes parcialmente desdentados, que receberam próteses fixas metalocerâmicas, unitárias ou múltiplas. Como controle, foram realizadas radiografias e avaliação das condições clínicas um ano após a instalação dos implantes, até a última análise. Os autores encontraram média de 1,77 para a proporção coroa/implante. No total, 26,5\% apresentaram proporção maior que 2. Ao final das análises, os autores concluíram que diferentes parâmetros como o modo de retenção da prótese, se unitária ou ferulizada, ou se com ou sem cantilever, não afetaram a perda óssea marginal ao redor dos implantes. Afirmam, por fim, que próteses implantossuportadas com proporção coroa/implante entre 2 e 3 podem ser utilizadas com segurança para restaurar desdentamentos posteriores.

Em 2008, Fugazzotto realizou um estudo retrospectivo com o objetivo de avaliar a longevidade de implantes curtos em diferentes situações clínicas. O estudo retrospectivo foi realizado entre maio de 2000 e maio de 2007 em pacientes que receberam implantes com comprimento inferior a $10 \mathrm{~mm}$. A idade do paciente, o gênero, a localização dos implantes, o tipo de prótese, o tempo em função e a estabilidade da crista óssea perimplantar foram avaliados. Nesses 7 anos de análise, 1.774 pacientes receberam 2.073 implantes de 6, 7, 8 e 9 mm de comprimento, instalados em diferentes situações clínicas. Para implantes reabilitados com restaurações unitárias ou pequenas próteses fixas, a porcentagem de sucesso clínico dos implantes foi de $98,1 \%$ a 99,7 \%. O autor concluiu ao final de seu estudo, que implantes de 6 a $9 \mathrm{~mm}$ de comprimento, quando colocados em função apropriadamente, apresentam longevidade semelhante aos implantes longos.

Grant et al., em um estudo retrospectivo publicado em 2009, analisaram o sucesso de implantes curtos de $8 \mathrm{~mm}$ de comprimento instalados na região posterior da mandíbula, 
restaurados com próteses fixas ferulizadas. Entre maio de 2005 e junho de 2007, 124 pacientes receberam 335 implantes com 8 mm de comprimento. Quatro desses implantes falharam, sendo que 2 foram instalados em regiões que receberam enxerto de hidroxiapatita e plasma rico em plaquetas. Após encontrarem 99\% de sucesso após 2 anos das próteses em função, os autores concluíram que implantes curtos podem ser indicados para reabilitações mandibulares em áreas que apresentem pouca altura óssea.

Em 2010, Anitua e Orive publicaram um estudo em que acompanharam por até 8 anos implantes curtos instalados tanto na maxila quanto na mandíbula. O objetivo dos autores foi avaliar de que maneira diferentes fatores influenciariam a longevidade clínica dos implantes. Foram instalados 1.287 implantes com comprimentos de 6,5 a 8,5 mm e diâmetros de 2,5 a 6 mm. O tempo médio de acompanhamento foi de 48 meses, sendo que apenas 9 implantes falharam durante esse período. Ao final do estudo os autores concluíram que implantes curtos podem ser utilizados com segurança, e creditam a elevada taxa de sucesso encontrada ao fato de que as próteses, em sua grande maioria, foram confeccionadas ferulizadas e não unitárias.

Raviv e equipe publicaram em 2010 uma revisão de literatura, acompanhada de um relato de caso, discutindo considerações biomecânicas que devem ser levadas em conta quando são utilizados implantes curtos. O caso clínico apresentado no estudo é de um implante de 6,0 x 6,0 mm, instalado na região do 16 com torque final de instalação de 32 N.cm, sendo imediatamente parafusado o cicatrizador, evitando a segunda cirurgia, para reabertura. Após o período de 6 meses a coroa metalocerâmica foi cimentada com cimento provisório sobre o intermediário. Como a paciente apresentava bruxismo, os autores deixaram leve contato oclusal em cêntrica e desoclusão tanto em lateralidade quanto em protrusão, além de confeccionarem placa miorrelaxante para uso noturno. Após 18 meses da instalação, foi observado sucesso estético e funcional da coroa. Os autores concluíram que implantes curtos podem ser utilizados com sucesso em casos unitários. 


\subsection{Fotoelasticidade}

Em 1949, Nooman realizou um estudo pioneiro, introduzindo o método de análise fotoelástica na odontologia. Nessa pesquisa, o autor aplicou forças sobre restaurações de amálgama confeccionadas em diferentes preparos cavitários realizados em blocos de resina com propriedade fotoelástica. Sob luz polarizada, a fim de determinar a forma de preparo que gerava menor quantidade de tensões, o autor verificou que amostras que possuíam preparos com ângulos arredondados induziram menor concentração de tensões.

Pouco tempo depois, Mahler e Peyton (1955) publicaram um artigo detalhando de que maneira a fotoelasticidade pode ser utilizada na odontologia, esclarecendo questões importantes acerca da metodologia como propagação e comprimento de onda da luz polarizada, indicando de que maneira se deve dar a incidência de luz, bem como os filtros necessários para a visualização das franjas isocromáticas.

Já Haraldson (1980) estudou pela primeira vez, pelo método fotoelástico, tensões induzidas por parafusos lisos de $3 \mathrm{~mm}$ de diâmetro, simulando implantes com ou sem roscas. Para tanto, o autor realizou três tipos de ancoragem: completa ancoragem óssea, perda óssea vertical e perda óssea horizontal. Assim, os parafusos foram imersos em resina fotoelástica (Araldite HY956) e após sua completa polimerização, receberam aplicações de cargas verticais (até 490 N) e horizontais (até 378 N). As imagens das tensões transmitidas aos parafusos foram fotografadas e analisadas. Os resultados mostraram que quando cargas verticais foram aplicadas, os implantes com roscas distribuíram a tensão ao longo das superfícies das roscas. Para os implantes lisos, foi observada concentração de tensão no ápice do implante, revelando que roscas na superfície do implante distribuem melhor a tensão. Quando foram aplicas cargas horizontais, a tensão transmitida ao redor dos parafusos foi muito mais nociva que quando aplicadas cargas verticais, revelando maior concentração de 
tensões nas simulações de perda óssea vertical e horizontal. Ao final do estudo o autor concluiu que quando analisado o padrão de distribuição de tensão, implantes com roscas promovem melhores resultados que implantes lisos.

Guichet et al. (2000) analisaram pelo método fotoelástico, o assentamento passivo e o desajuste marginal de próteses implantossuportadas (3 elementos unidos) parafusadas ou cimentadas, simulando reabilitação de mandíbula esquerda por 3 implantes (3,75 x 10 mm). Após verificar, com auxílio de microscópio, a desajuste marginal tanto pela vestibular quanto pela lingual de cada um dos elementos das próteses, os autores verificaram que não houve diferença entre os sistemas de retenção avaliados. Para as próteses parafusadas, o aperto do parafuso resultou em diminuição dos valores de desajuste marginal, já para as próteses cimentadas, a presença do cimento não alterou esses valores. Quanto à análise fotoelástica de tensões, os autores concluíram que as próteses cimentadas transferiram tensões à região adjacente aos implantes de maneira mais uniforme que as parafusadas.

Em 2002, Guichet et al. avaliaram o efeito da união e do contato proximal efetivo na passividade e as características de transferência de tensões por próteses implantossuportadas. Foi confeccionado modelo fotoelástico simulando mandíbula esquerda reabilitada por três implantes (3,75 x $10 \mathrm{~mm})$. Para as próteses unitárias foram utilizados três intermediários preparáveis e para as próteses unidas foram confeccionadas 5 próteses de três elementos, todas cimentadas sobre os intermediários. Após a cimentação, 5 diferentes níveis de espessura de contato proximal foram realizados: aberto, ideal $(8 \mu \mathrm{m})$, leve $(10 \mu \mathrm{m})$, médio $(50 \mu \mathrm{m})$ e forte $(90 \mu \mathrm{m})$ e as alterações na distribuição de tensões foram analisadas com polariscópio. Para as próteses unitárias, os autores encontraram que o maior contato proximal gerou aumento de concentração de tensões entre os implantes, que se concentraram no implante que recebia a aplicação de carga. Os autores concluíram que o contato proximal excessivo entre 
próteses unitárias pode gerar situação de não passividade e ressaltam ainda que as próteses unidas promoveram melhor distribuição de tensões que as unitárias.

Cehreli et al. (2004) realizaram um estudo em que compararam de que maneira tensões aplicadas a implantes com conexão hexágono externo e cone morse seriam transmitidas à região adjacente ao implantes. Os autores compararam três marcas diferentes de implantes (Branemark, ITI e Astra Tech) pelo método fotoelástico e também por extensiometria. Sobre o componente protético, foram aplicadas, separadamente em carregamentos individuais, forças verticais e oblíquas $\left(20^{\circ}\right)$ de 100 e 150 N. Os padrões de franjas isocromáticas obtidos adjacentes aos implantes, foram fotografados e avaliados. As medidas de extensiometria foram analisadas e a tensão induzida na região adjacente a cada implante foi calculada. Como resultado, os pesquisadores encontraram quantidade de ordens de franja semelhantes entre os implantes, para todas as situações avaliadas. Quanto à extensiometria, os autores observaram que a concentração de tensão adjacente ao implante do tipo Branemark foi menor que nos demais, que por sua vez apresentaram valores similares, sendo que os implantes cônicos Astra Tech apresentaram menores tensões sob carga vertical. Assim, concluíram que tanto a junção externa quanto a cônica interna tiveram características de distribuição de tensão semelhantes, ressaltando que a conexão implante/intermediário não foi decisiva no que se refere à distribuição e magnitude de tensões à região perimplantar.

Bernardes et al. (2009) realizaram estudo fotoelástico em que estudaram de que maneira cargas aplicadas no centro e a $6,5 \mathrm{~mm}$ do implante transferem tensões a regiões perimplantares. Foram confeccionados implantes sem roscas e cilíndricos, que foram imersos em resina fotoelástica com 4 interfaces protéticas diferentes: hexágono externo, hexágono interno, cone morse e corpo único. Sobre os implantes, quando necessário, os intermediários foram adaptados, e então submetidos à carga de 1,5 Kg aplicada no centro do implante e 0,75 Kg aplicada a 6,5 mm do centro. As tensões máximas foram determinadas e observadas em 46 
pontos para a aplicação no centro do implante e em 61 pontos para a aplicação a 6,5 mm do centro, expressas por gráficos. Os autores encontraram como resultado de seu estudo que a aplicação de carga no centro do implante transmitiu tensões de valores semelhantes, não havendo diferença estatística entre os quatro tipos de junções avaliadas. Quando a carga foi aplicada a 6,5 mm do centro do implante, os menores valores de tensões foram encontrados, para todos os pontos, para a conexão do tipo hexágono interno, com diferença estatística significante. Ao final do estudo foi possível concluir que a junção que melhor distribuiu tensões foi a de hexágono interno, sendo que as de corpo único e hexágono externo transmitiram os maiores valores.

Ainda pelo método fotoelástico, Pellizzer e colaboradores (2010) estudaram de que maneira tensões são transmitidas a implantes do tipo hexágono externo, por próteses de três elementos (segundo pré-molar, primeiro molar como pôntico, e segundo molar). Para tanto, os autores confeccionaram dois modelos fotoelásticos com implantes nas regiões correspondentes ao segundo pré-molar e ao segundo molar, sobre os quais foram confeccionadas próteses em liga de NiCr, ou parafusadas ou cimentadas sobre os implantes. Na superfície oclusal de cada elemento, foi aplicada carga pontual de $100 \mathrm{~N}$, ora paralela ao longo eixo do implante (axial) ora oblíqua $\left(45^{\circ}\right)$. Os autores fotografaram a distribuição de ordens de franjas e ao analisá-las encontraram maiores tensões para o modelo com próteses parafusadas, tanto para a carga axial, quanto para a oblíqua, independente da região aplicada. Concluíram também que as cargas quando eram aplicadas de maneira oblíqua promoviam maior concentração de tensões adjacentes aos implantes, quando comparadas às cargas axiais.

Menani et al. (2011), estudaram pelo método fotoelástico o comportamento biomecânico de próteses parciais fixas metalocerâmicas e metaloplásticas, unidas e unitárias, cimentadas sobre pilares parafusados em implantes do tipo Cone Morse. Foi utilizado um modelo fotoelástico com a presença do primeiro pré-molar inferior e do segundo molar, 
simulados em resina, além de implantes que foram utilizados para reabilitar os espaços correspondentes ao segundo pré-molar e ao primeiro molar. Os implantes receberam quatro tipos de próteses cimentadas: próteses unidas em cerâmica ou em resina, e próteses unitárias também confeccionadas em cerâmica ou em resina. Sobre as próteses os autores aplicaram carga oclusal distribuída e também cargas pontuais ou na mesial do segundo pré-molar ou na distal do segundo molar. Após análise fotoelástica qualitativa das tensões transmitidas à região perimplantar, os autores concluíram que próteses metalocerâmicas transmitiram menos tensão ao redor dos implantes, e também encontraram menor concentração de tensões quando foram utilizadas próteses unidas, quando comparadas com as unitárias.

Em recente artigo (2011), Torres et al. estudaram a tensão transmitida a implantes por diferentes estruturas fundidas em diferentes materiais e de que maneira desajustes verticais influenciariam a distribuição dessas tensões. Os autores confeccionaram estruturas em titânio comercialmente puro, liga de cobalto-cromo e de níquel-cromo. Todas as estruturas foram instaladas com torque de 10 N.cm nos parafusos e foi realizada medição em microscópio do desajuste vertical dessas estruturas. As tensões transmitidas à região interimplantar foi avaliada quantitativamente pelo método fotoelástico e os autores concluíram que as estruturas confeccionadas em liga de cobalto-cromo transmitiram mais tensões que as demais, e não encontraram correlação direta entre os desajustes e as tensões encontradas ao redor do implantes, para nenhuma das estruturas utilizadas. 
PROPOSIÇÃO 


\section{PROPOSIÇÃo}

A presente pesquisa teve como objetivo geral avaliar o desempenho biomecânico de prótese parciais fixas parafusadas e ferulizadas sobre implantes Cone Morse curtos posicionados em área posterior de mandíbula, por meio de análise fotoelástica, qualitativa e quantitativa, das tensões geradas em torno dos implantes.

Os objetivos específicos foram:

- $\quad$ Avaliar a distribuição de tensões em diferentes associações de implantes curtos e convencionais;

- Avaliar a influência da altura das coroas sobre a distribuição de tensão em torno dos implantes;

- $\quad$ Avaliar o efeito de diferentes carregamentos oclusais sobre estas próteses. 
MATERIAL E MÉTODO 


\section{MATERIAL E MÉTODO}

\subsection{Obtenção dos modelos mestres}

Foram confeccionados 4 modelos mestres em policarbonato, no formato de bloco retangular $(68 \times 30 \times 15 \mathrm{~mm})$, contendo uma réplica em resina de um primeiro pré-molar inferior (Luxatemp, DMG, Hamburgo, Alemanha) e três réplicas de implantes, correspondentes ao segundo pré-molar inferior, primeiro e segundo molares inferiores. Para tanto, cada bloco recebeu quatro perfurações com diâmetro e profundidade compatíveis com o dente e as réplicas que foram posteriormente fixadas. A distância entre as perfurações foram, entre pré-molares $7,5 \mathrm{~mm}$, entre o segundo pré-molar e o primeiro molar 9,5 $\mathrm{mm}$, e entre os molares foi 11,5 mm (OTUYEMI, NOAR, 1996; BERNABÉ, FLORES-MIR, 2006).

Com auxílio de um paralelômetro, as réplicas dos dentes e dos implantes foram posicionadas com seus longos eixos paralelos entre sim, reproduzindo uma condição clínica de posicionamento ideal dos implantes, e fixados às perfurações utilizando cola à base de cianoacrilato (Super Bonder, Loctite, Brasil) (Figura 01).

O grupo 1 apresentava réplicas de implantes Titamax Cortical CM 4.0 x $11 \mathrm{~mm}$, correspondentes aos segundo pré-molares e primeiro molar inferiores, e Ws Cortical CM 4.0 x $5 \mathrm{~mm}$ correspondente ao segundo molar. O grupo 2 apresentava réplicas de implantes Titamax Cortical CM $4.0 \times 11 \mathrm{~mm}$, correspondente ao segundo pré-molar inferior, e Ws Cortical CM 4.0 x $5 \mathrm{~mm}$ substituindo o primeiro e segundo molares inferiores. O grupo 3 apresentava 3 réplicas de implantes Ws Cortical CM 4.0 x $5 \mathrm{~mm}$ correspondentes ao segundo pré-molar, primeiro e segundo molares inferiores. Já o grupo 4 apresentava 3 réplicas de implantes Titamax Cortical CM 4.0 x $11 \mathrm{~mm}$ correspondentes ao segundo pré-molar, primeiro e segundo molares inferiores (Figura 01). Para os grupos 1, 2 e 3, onde foram utilizadas 
réplicas de implantes curtos (Ws Cortical CM 4.0 × $5 \mathrm{~mm}$ ), foi confeccionado no modelo reabsorção óssea de $4 \mathrm{~mm}$, simulando a pouca altura óssea e a conseqüente proximidade ao nervo alveolar inferior, justificando a utilização de implantes com comprimentos menores. As réplicas correspondentes aos implantes com $11 \mathrm{~mm}$ de comprimento foram afixadas $2 \mathrm{~mm}$ abaixo da superfície do modelo, já as réplicas dos implantes curtos ( $5 \mathrm{~mm}$ de comprimento) foram posicionadas ao nível da superfície do modelo, seguindo a indicação do fabricante, a respeito da posição óssea ideal (Figura 02).
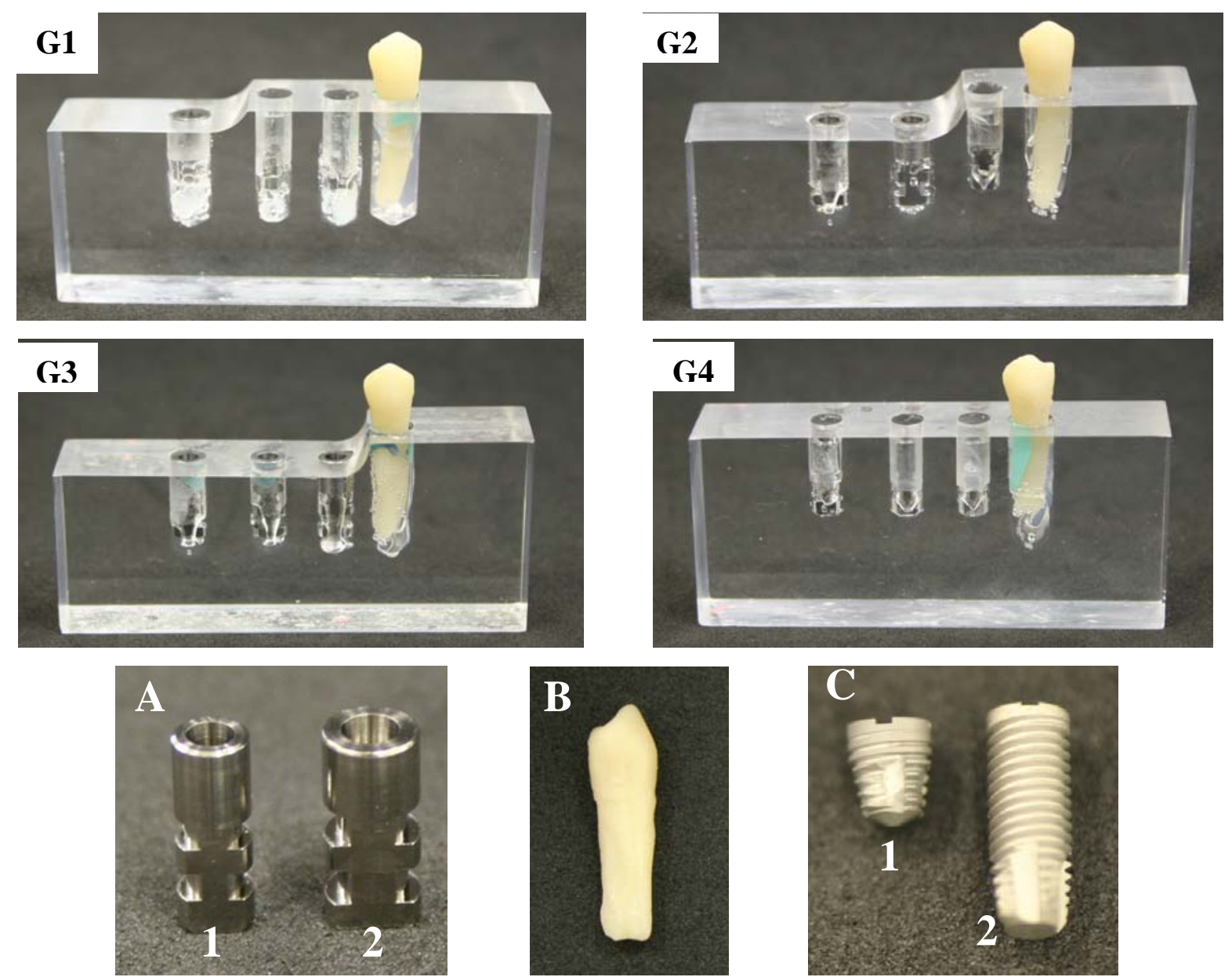

Figura 01. Modelos mestres com o primeiro pré-molar inferior direito e os análogos já fixados, para cada grupo: G1- grupo 1; G2 - grupo 2; G3- grupo 3 e G4 - grupo 4. A- Vista aproximada dos análogos (1 - análogo do Titamax Cortical CM 4 x $11 \mathrm{~mm}$; 2- análogo do Ws Cortical CM 4 x $5 \mathrm{~mm}$ ); B - Primeiro pré-molar em resina. C - Implantes (1 - Titamax Cortical CM 4 x 11 mm; 2 - Ws Cortical CM 4 x 5 mm). 

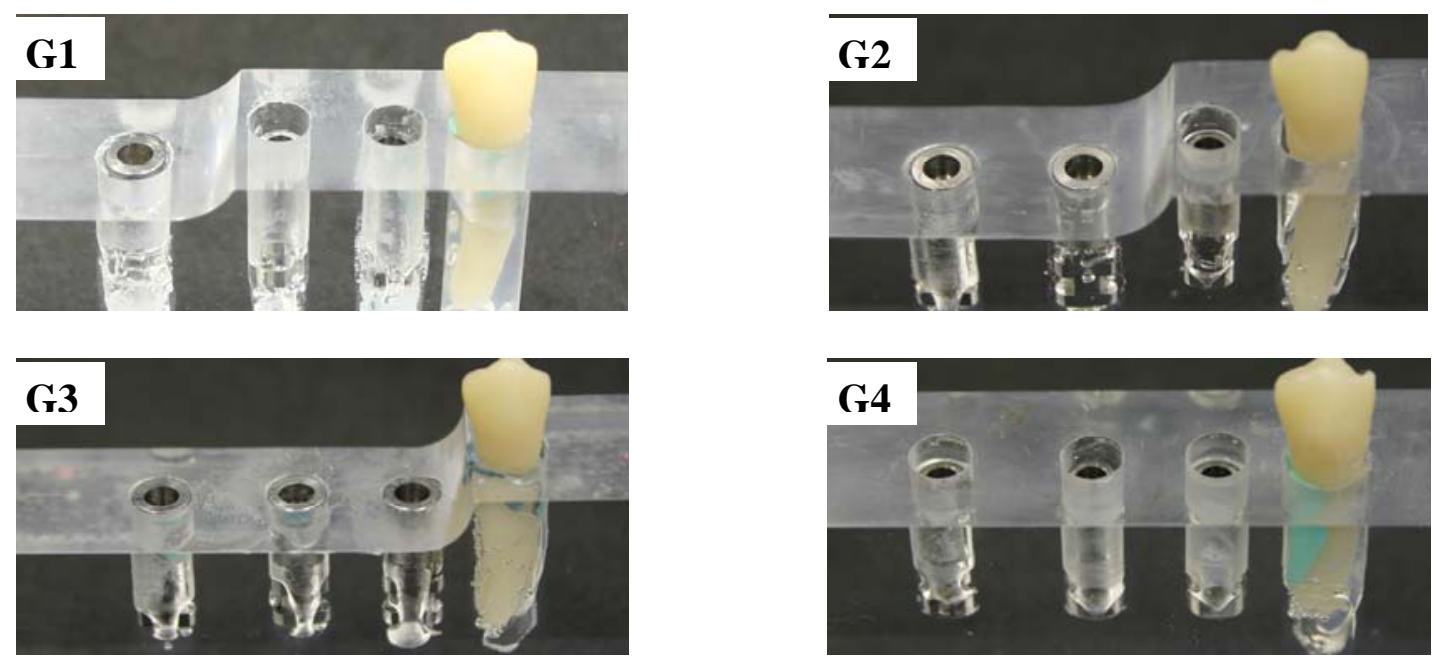

Figura 02. Vista aproximada dos Grupos 1, 2, 3 e 4 detalhando o posicionamento dos análogos nos modelos mestres.

Sobre as réplicas dos implantes foram instalados pilares intermediários utilizados em reabilitações ferulizadas parafusadas. Sobre cada réplica do implante de comprimento convencional foi utilizado Mini Pilar Cônico CM 3,5 mm, e para cada réplica do implante curto foi utilizado Mini Pilar Cônico Ws 0,8 mm (Figura 3). Todos os intermediários foram parafusados em suas respectivas réplicas com torque de 20 N.cm calibrado pelo uso de catraca torquímetro (Neodent, Curitiba, Brasil). 

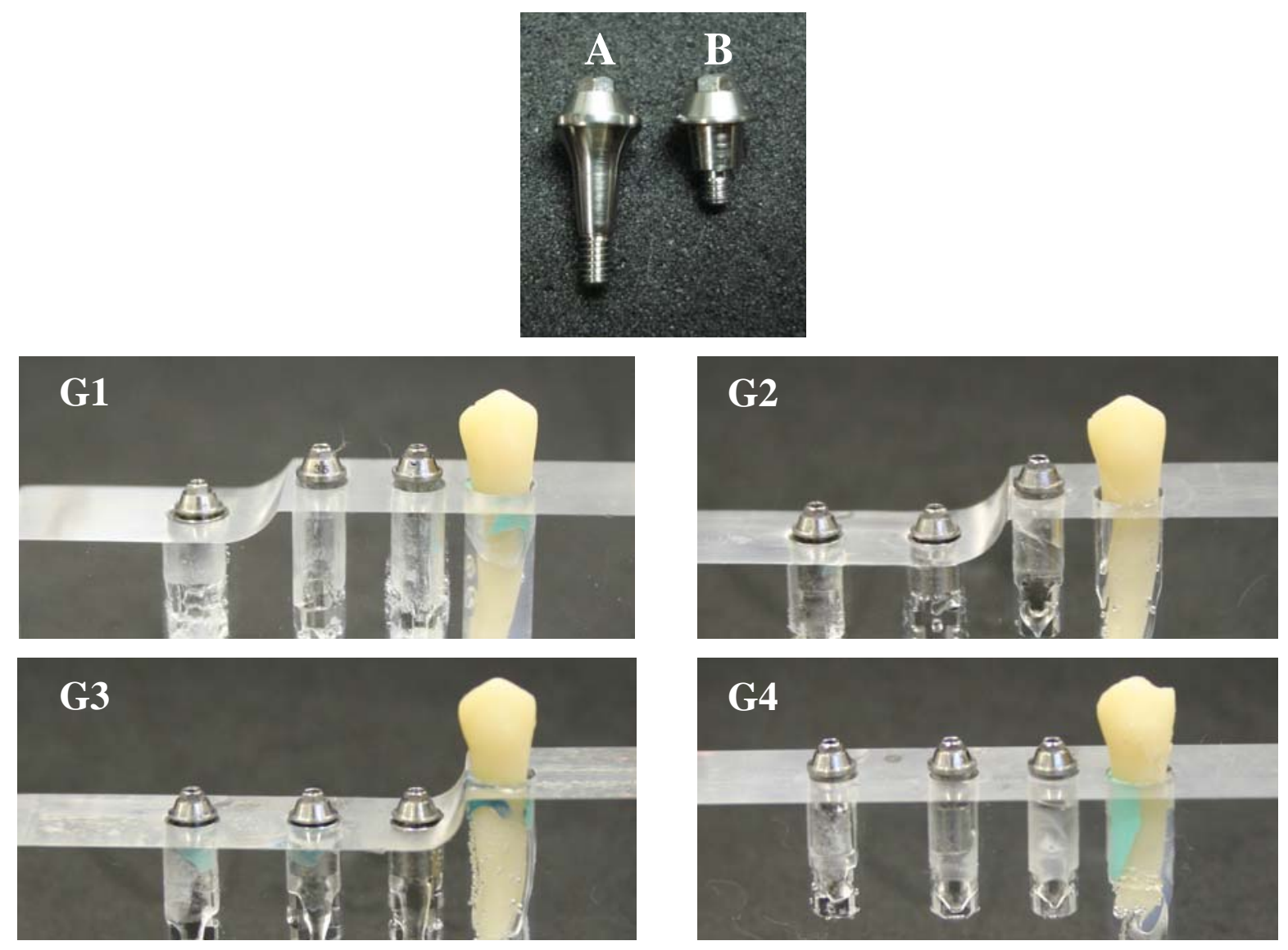

Figura 03. A- Mini Pilar para implantes de comprimento convencional; B- Mini Pilar para implantes curtos. G1, G2, G3 e G4 - Vista aproximada dos Mini Pilares parafusados nas réplicas de seus respectivos grupos.

\subsection{Obtenção dos enceramentos}

Após os Mini Pilares Cônicos serem parafusados em seus respectivos modelos mestres, Cilindros Calcináveis para Mini Pilar Cônico foram seccionados com disco de carborundum adaptados em peça reta, de maneira que as alturas de corte foram padronizadas com auxílio de paquímetro digital (Mitutoyo, Nagoya, Japão) para que após a fundição os cilindros tivessem a mesma quantidade e altura de metal. Os Cilindros Calcináveis para os Mini Pilares Cônicos dos implantes de comprimento convencional mediam $5 \mathrm{~mm}$ de altura, enquanto que para os implantes curtos mediam $8 \mathrm{~mm}$ (Figura 04). 

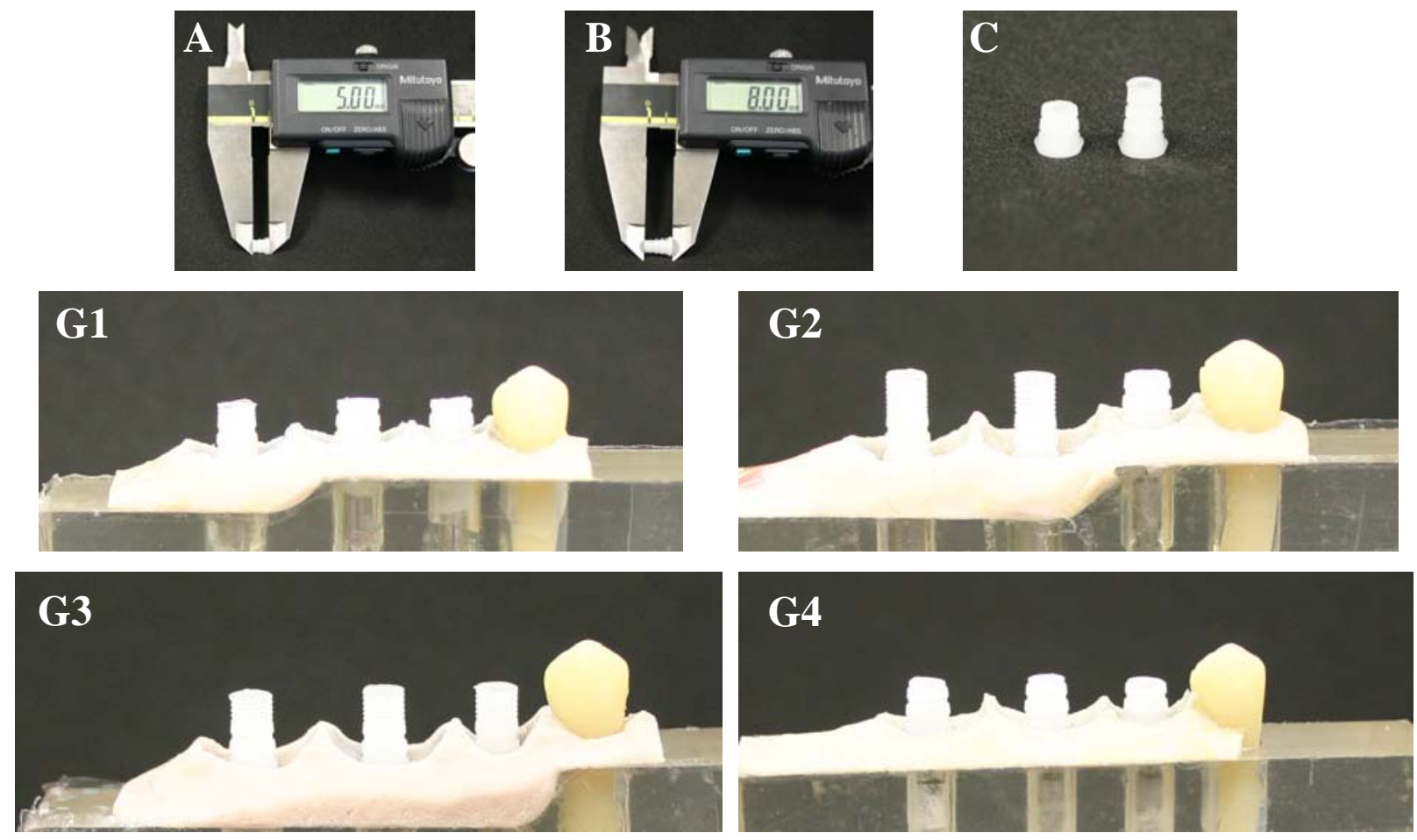

Figura 04. A e B - Padronização das alturas dos cilindros calcináveis respectivamente para os implantes longos e cutos; C - Cilindros calcináveis já cortados. G1, G2, G3 e G4 - Cilindros calcináveis adaptados sobre seus respectivos Mini Pilares.

Para cada grupo foram encerados sobre os cilindros calcináveis três coroas unidas, e em seguida, foi confeccionada gengiva artificial em torno da réplica do dente e desses enceramentos com silicone (Zetalabor, Zhermack, Rovigo, Itália), e também obtida uma matriz bipartida, também em silicone (Zetaplus e Oranwash, Zhermack), para cada um dos grupos (Figura 05). 

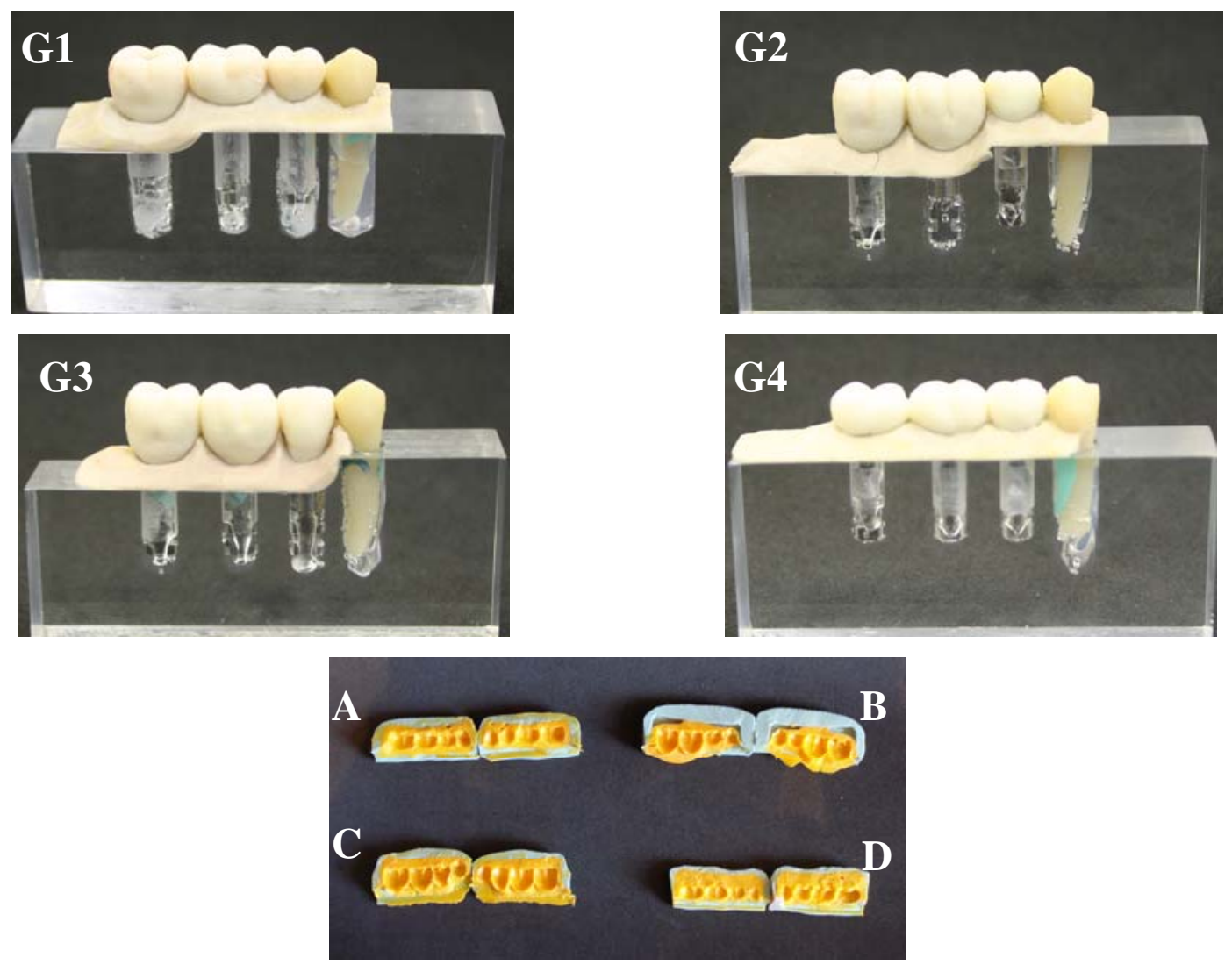

Figura 05. G1, G2, G3 e G4 com gengiva artificial em silicone e enceramentos dentais. A, B, C e D - Matrizes bipartidas dos enceramentos dos grupos G1, G2, G3 e G4, respectivamente.

A partir das matrizes bipartidas, sobre novos Cilindros Calcináveis foram obtidos outros enceramentos em cera para escultura (Schuler Dental, Alemanha). A cera liquefeita em plastificador com controle digital de temperatura (Hotty Led, Renfert GmbH, Hilzingen, Alemanha), mantida a $90^{\circ} \mathrm{C}$, foi depositada na matriz bipartida e levada ao respectivo modelo mestre, obtendo-se assim réplicas do enceramento original. Esses novos enceramentos obtidos foram reduzidos no formato adequado para infra-estruturas metálicas e seccionados com lâmina, para posterior soldagem à laser (Figura 06). 

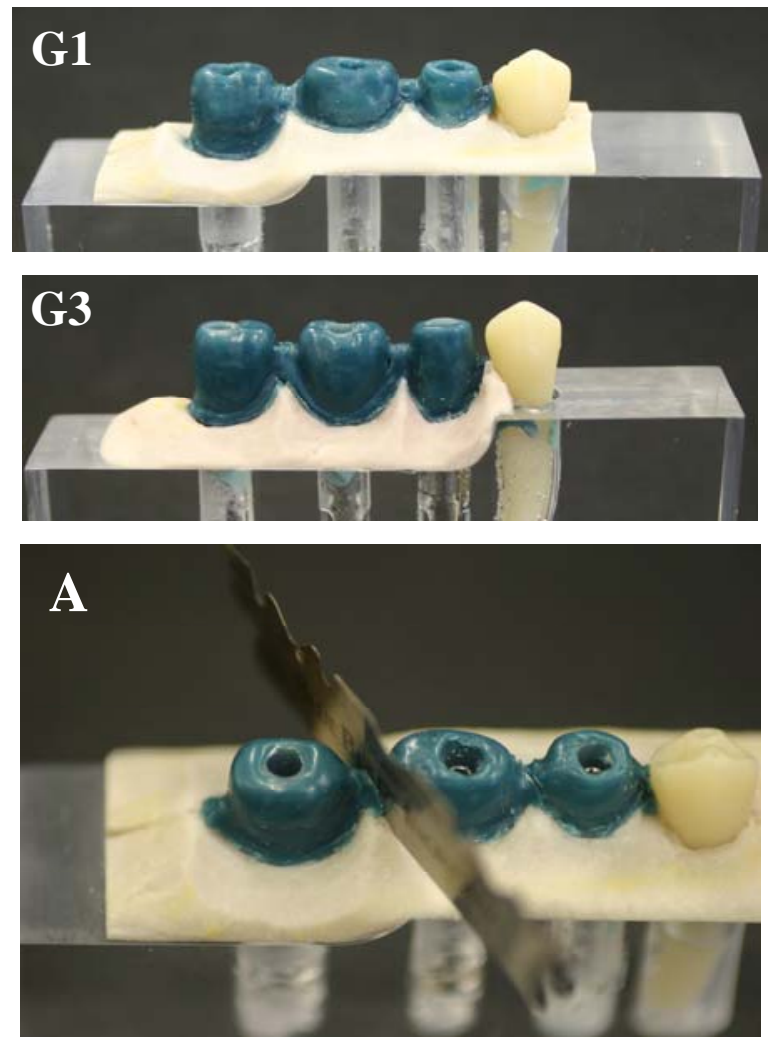

Figura 06. G1, G2, G3 e G4 com seus respectivos enceramentos reduzidos para as subestruturas metálicas. A Secção dos enceramentos com lâmina de bisturi para posterior soldagem a laser; $\mathbf{B}$ - Vista aproximada do enceramento já seccionado, em duas regiões.

\subsection{Inclusão, fundição e soldagem à laser das estruturas metálicas}

Sobre a superfície dos enceramentos foram posicionados sprues pré-fabricados (Pasom, São Paulo-SP, Brasil), numa angulação de aproximadamente $45^{\circ}$. Os padrões de cera assim preparados foram fixados com cera 7 às bases formadoras de cadinho, pulverizados com spray redutor de tensão de superfície (Waxit, DeguDent GmbH, Hanau-Wolfgang, Alemanha) e deixados secando à temperatura ambiente. Em seguida, os enceramentos foram unidos com cera 7 à base conformadora de cadinho, para posterior inclusão em anel de silicone para fundição (Figura 07).

A inclusão foi realizada em duas etapas. O revestimento Heat Shock (Dentaurm, Ispringen, Alemanha) foi proporcionado segundo recomendações do fabricante, utilizando-se 
$20 \mathrm{~g}$ do pó mais 4,53 $\mathrm{mL}$ do líquido para a boneca e $200 \mathrm{~g}$ do pó mais $45,33 \mathrm{~mL}$ do líquido para o preenchimento do anel de fundição $\mathrm{O}$ revestimento foi espatulado mecanicamente a vácuo por 60 segundos em espatulador elétrico (Turbomix, EDG Equipamentos e Controles Ltda., São Carlos-SP, Brasil) e foi cuidadosamente pincelado na superfície interna dos cilindros para a confecção da boneca. Completou-se posteriormente o preenchimento do anel sob vibração, para evitar a formação de bolhas. Os anéis assim preparados ficaram sobre a bancada à temperatura ambiente, até o início da reação de cristalização do revestimento (Figura 07). Após cerca de 40 minutos, o anel de silicone foi removido e os revestimentos foram levados ao forno elétrico para expansão do revestimento e eliminação da cera, empregando-se o ciclo térmico de $250^{\circ} \mathrm{C}$ na primeira hora e elevação da temperatura a $950^{\circ} \mathrm{C}$ com velocidade de aquecimento de $5^{\circ} \mathrm{C} / \mathrm{min}$, aguardando-se meia hora após o final do ciclo para realizar a fundição em centrífuga para fundição com acionamento elétrico (EDG, São Carlos, Brasil).

Após o processo de fundição e adequado resfriamento do revestimento, as estruturas foram desincluídas e jateadas com óxido de alumínio (Polidental Indústria e Comércio Ltda.) de granulação de $100 \mu \mathrm{m}$, sob pressão de $80 \mathrm{lib} / \mathrm{pol}^{2}$. Os condutos de alimentação foram seccionados com discos de carborundum e foram removidos apenas pequenos nódulos e irregularidades. Assim, foi possível adaptar as infra-estruturas aos modelos (Figura 07).

Para a realização da soldagem à laser, as partes foram posicionadas em seus respectivos modelos mestres e receberam o torque de 10 N.cm, recomendado pelo fabricante. A máquina de solda a laser (Desktop, Dentaurum, Ispringen, Alemanha) foi ajustada em 310V e pulso de $9 \mathrm{~ms}$, realizando-se inicialmente dois pontos de solda em regiões diametralmente opostas e prosseguindo-se com soldagem das regiões restantes (Figura 07). 

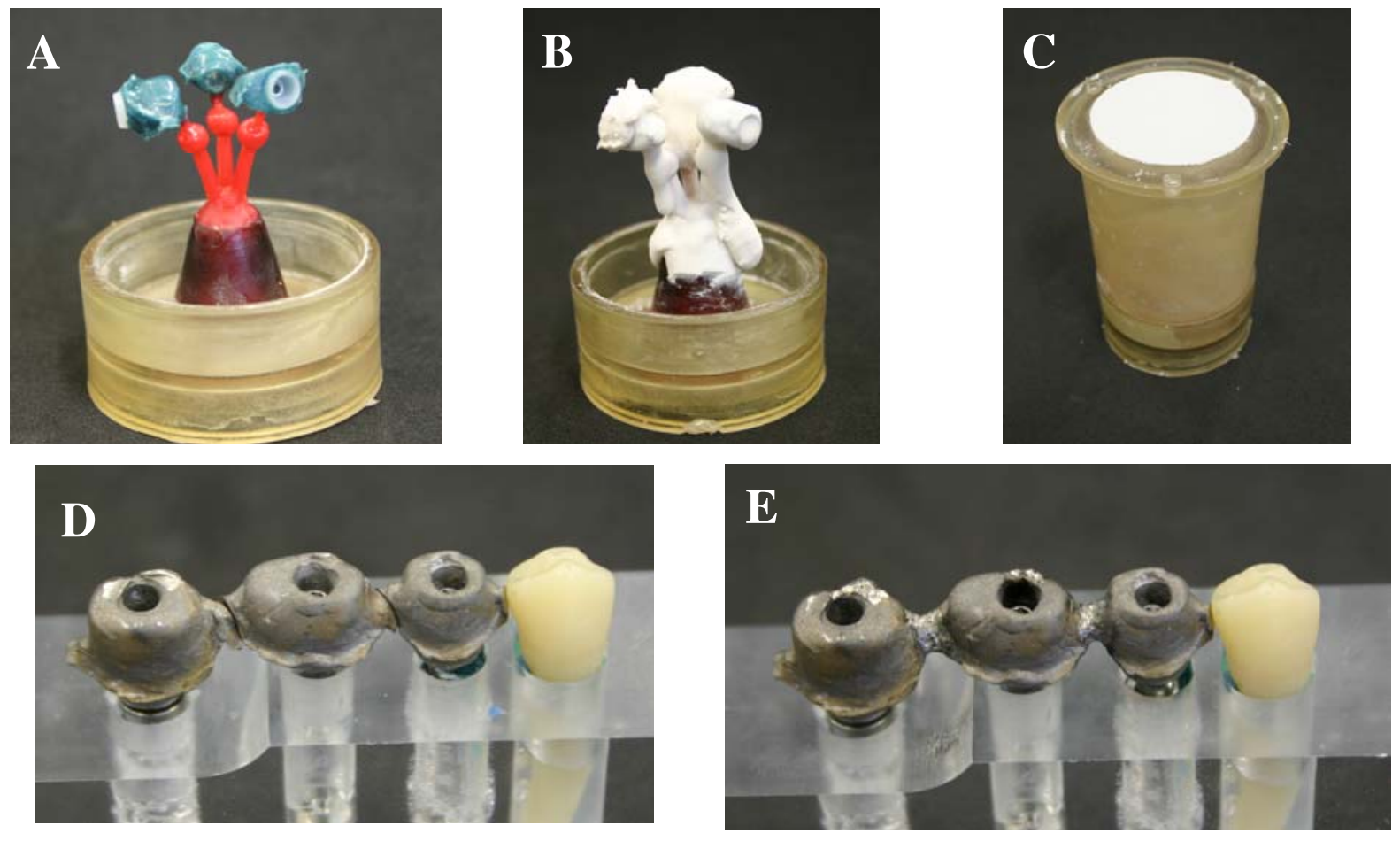

Figura 07. A- Enceramentos fixados às bases conformadoras de cadinho. B- Boneca confeccionada. C - Anel de silicone já preenchido com revestimento. D - Estrutura metálica parafusada sobre seu respectivo modelo mestre. E - Estrutura metálica já soldada.

Após a realização da solda a laser, em todas as estruturas foram realizadas medidas do desajuste cervical entre cada um dos elementos das próteses em Estereomicroscópio S8APO (Leica Microsystems, Heeburg, Suíça) com câmera digital DFC 250 (Leica Microsystems). Para tanto, apenas o parafuso de um elemento de uma extremidade da prótese foi parafusado e realizadas 3 medidas na vestibular e outras 3 na lingual de cada uma das coroas, e em seguida, o elemento da extremidade oposta foi parafusado e realizadas leituras da mesma maneira descrita anteriormente (Aparício, 1999). 


\subsection{Aplicação do opaco e prensagem da cerâmica}

Após a realização da solda à laser, as quatro estruturas receberam aplicação de 2 camadas de opaco (IPS In Line PoM Opaquer, A1, Ivoclar Vivadent, Liechtenstein), sinterizadas de acordo com as recomendações do fabricante (Figura 08).
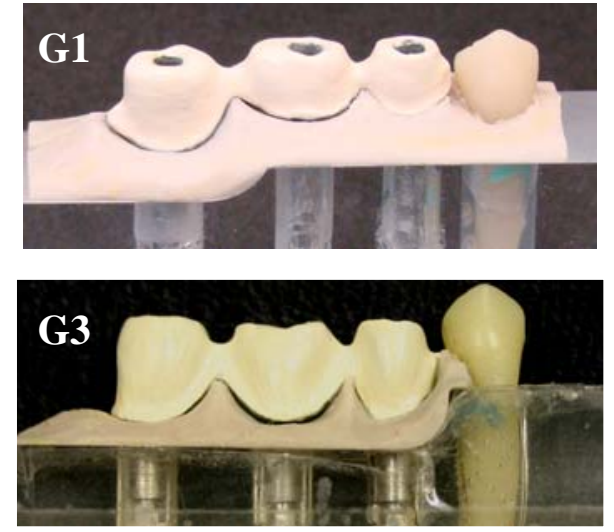
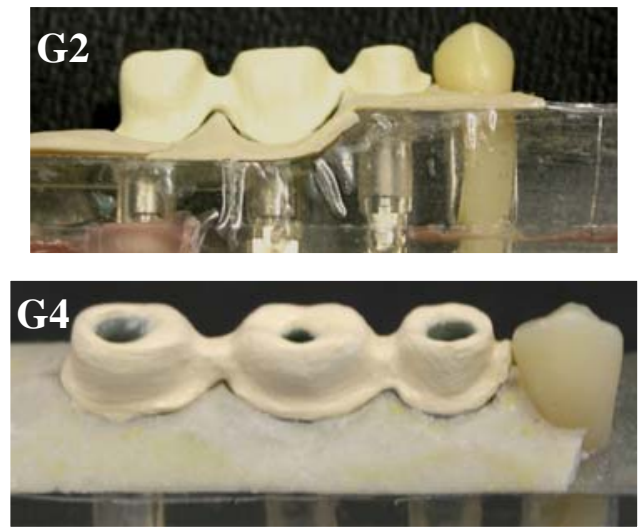

Figura 08. G1, G2, G3 e G4 - Grupos após receberem aplicação de duas camadas de opaco.

Em seguida, novo enceramento foi realizado, nesse caso, sobre a cerâmica opaca. Para tanto, as estruturas metálicas com o opaco aplicado, foram parafusadas em seus respectivos modelos mestres (torque de 10 N.cm) e foi novamente utilizada cera para escultura liquefeita (Schuler Dental), aplicada sobre a matriz bipartida em silicona, obtida a partir do enceramento inicial das coroas (Figura 09).

Sobre a superfície dos enceramentos foram posicionados sprues pré-fabricados (Pasom, São Paulo-SP, Brasil), numa angulação de aproximadamente $45^{\circ}$, nas cúspides linguais dos elementos. Os padrões de cera assim preparados foram fixados com cera branca (Cera Geo Cervical, Renfert, Renfert, Hilzingen, Alemanha) às bases formadoras de cadinho. A seguir, foi manipulado revestimento IPS Press Vest (Ivoclar Vivadent, Liechtenstein) em espatulador a vácuo (Turbomix, EDG Equipamentos e Controles Ltda.), seguindo proporção recomendada pelo fabricante (200 g do revestimento, $26 \mathrm{~mL}$ do líquido e $18 \mathrm{~mL}$ de água 
destilada), incluídas em anel de silicone específico (Ivoclar Vivadent, Liechtenstein). Assim, cada anel foi levado ao forno EP 500 (Ivoclar Vivadent) para prensagem de uma pastilha de tamanho "S" da cerâmica IPS In Line POM cor A1 (Ivoclar Vivadent, Liechtenstein), seguindo a programação recomendada pelo fabricante. Após a prensagem, os condutos de alimentação foram seccionados com disco diamantado e a superfície das próteses foi polida com borrachas abrasivas, para posteriormente serem submetidas ao glaze, seguindo temperaturas e tempo de cocção indicados pelo fabricante (Figura 10).

O ponto de contato entre o primeiro e segundo pré-molares foram marcados com auxílio de carbono (AccuFilm II, Parkel, EUA) e ajustados a fim de obter a maior uniformidade possível.

Ao final de todo esse processo, as próteses estavam prontas e adequadamente adaptadas sobre seus respectivos modelos mestres (Figura 11).
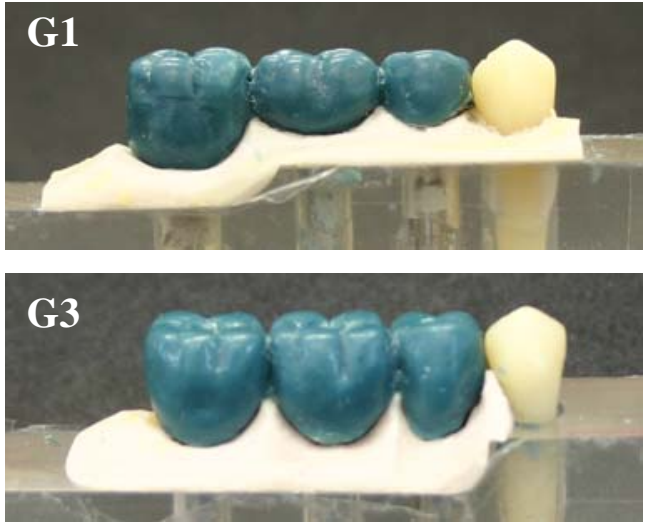
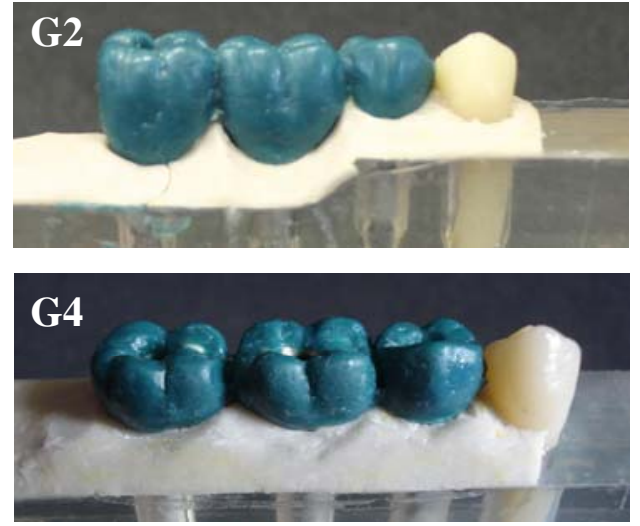

Figura 09. G1, G2, G3 e G4 - Enceramentos realizados sobre as cerâmicas opacas, obtidos com auxilio de suas respectivas matrizes bipartidas. 

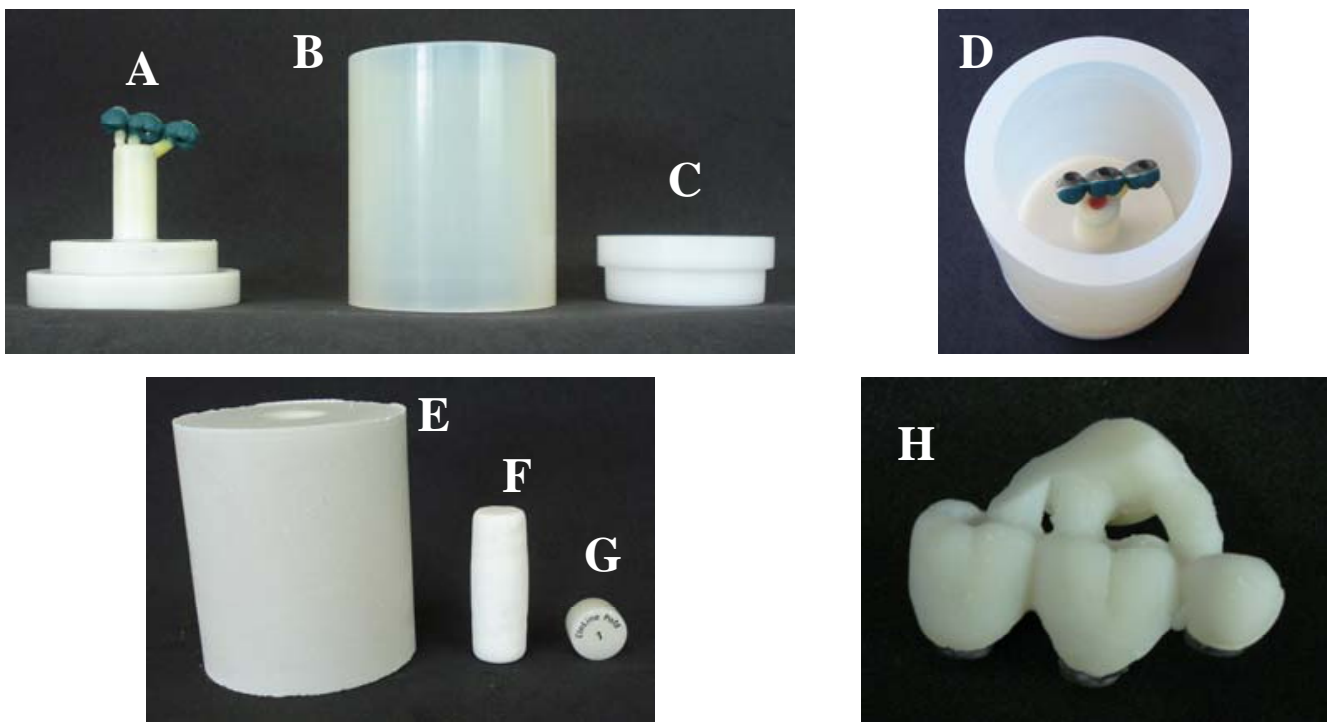

Figura 10. A - Enceramentos fixados a base conformadora de cadinho, B - Anel de silicone específico, C Parte superior do anel, D - Vista aproximada do posicionamento do enceramento no anel de silicone, E Enceramento já incluído em revestimento, F - Êmbolo utilizado durante a prensagem da cerâmica, $\mathbf{G}$ - Pastilha de cerâmica IPS In Line POM (cor A1) utilizada para prensagem, e H - Resultado obtido após a prensagem da cerâmica.
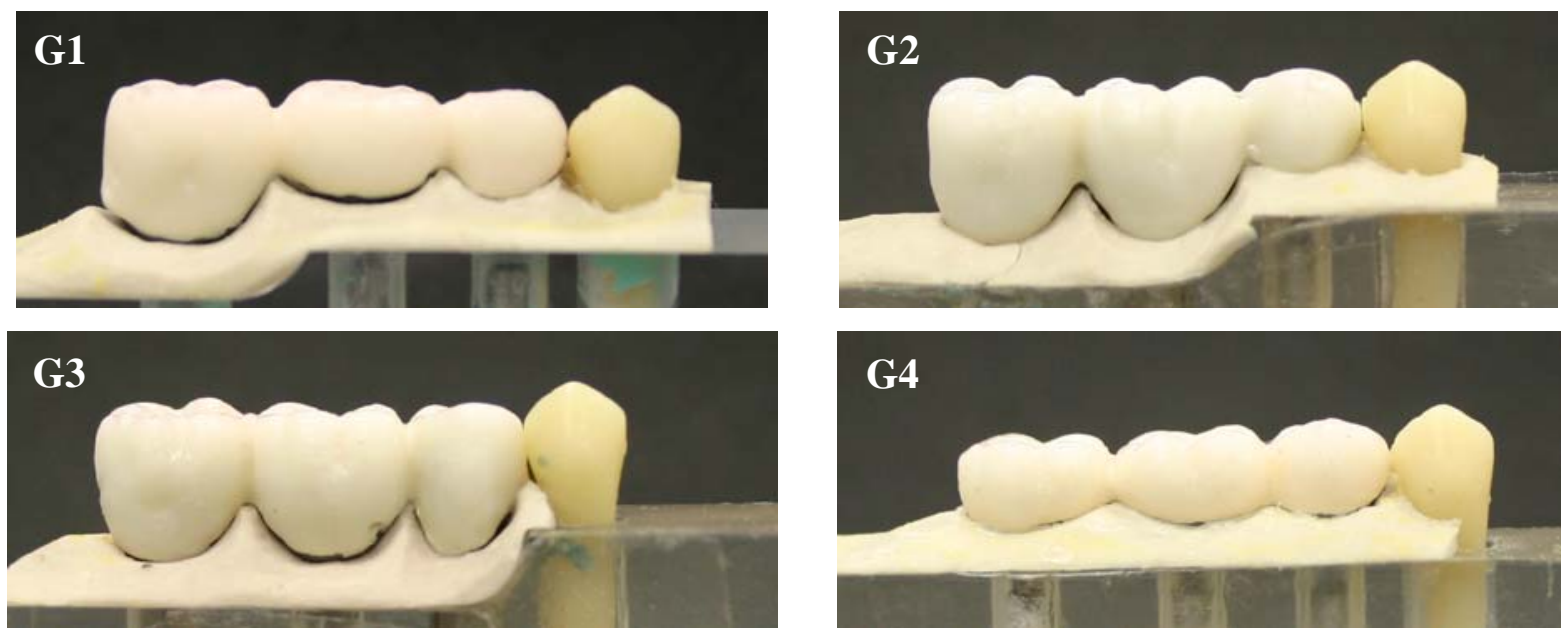

Figura 11. G1, G2, G3 e G4 - Coroas metalocerâmicas finalizadas, parafusadas em seus respectivos modelos mestres.

\subsection{Obtenção dos modelos fotoelásticos}

A verificação das tensões geradas em torno dos implantes foi realizada por meio de análise fotoelástica de transmissão qualitativa e quantitativa, em pontos pré-determinados, ambas sob aplicação de carga cêntrica estática. 
Para obtenção dos modelos fotoelásticos, foram confeccionados moldes em silicone (Silicone Master, Talladium, Curitiba, Brasil), cujas câmaras de molde reproduziram a forma dos dentes e as posições exatas dos dentes e implantes do modelo mestre. Para a confecção dos moldes, transferentes de moldagem (Neodent) foram parafusados sobre os mini-pilares no modelo mestre e foram unidos entre si com brocas velhas e resina acrílica Duralay, confeccionando um índex. Cada grupo possuía seu respectivo índex e molde, já que as posições dos mini-pilares eram diferentes (Figura 12).
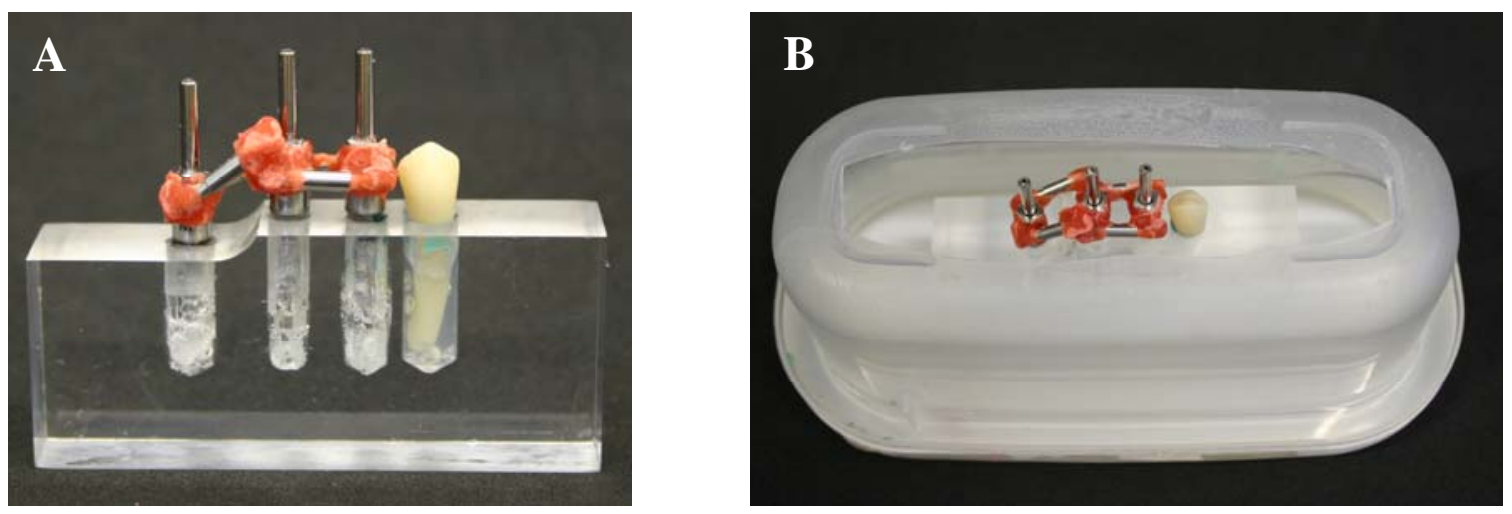

Figura 12. A - Transferentes de moldagem adaptados aos mini-pilares do G1, unidos com broca velha e resina acrílica Duralay. B- Caixa molde onde foi vertido o Silicone Master.

Para inclusão da resina fotoelástica, as réplicas dos dentes receberam uma cobertura de Impregum Soft (3M ESPE, Seefeld, Alemanha) na sua porção radicular, com o intuito de simular o ligamento periodontal (Rabitz et al., 2006; Soares et al., 2006). A raiz do primeiro pré-molar foi imersa em banho de cera para escultura (Schuler Dental) numa espessura aproximada de $300 \mu \mathrm{m}$ (Hohmann et al., 2007). As raízes com banho de cera foram moldadas com silicone de adição (Felixitime, Heraeus Kulzer), após a presa do material os dentes foram removidos e, desta forma, foi criado um molde para obtenção padronizada do ligamento periodontal simulado. A réplica do primeiro pré-molar com ligamento periodontal simulado e 
os implantes com o respectivo mini-pilar parafusado foram encaixados na matriz de silicone, previamente à manipulação de resina (Figura 13).
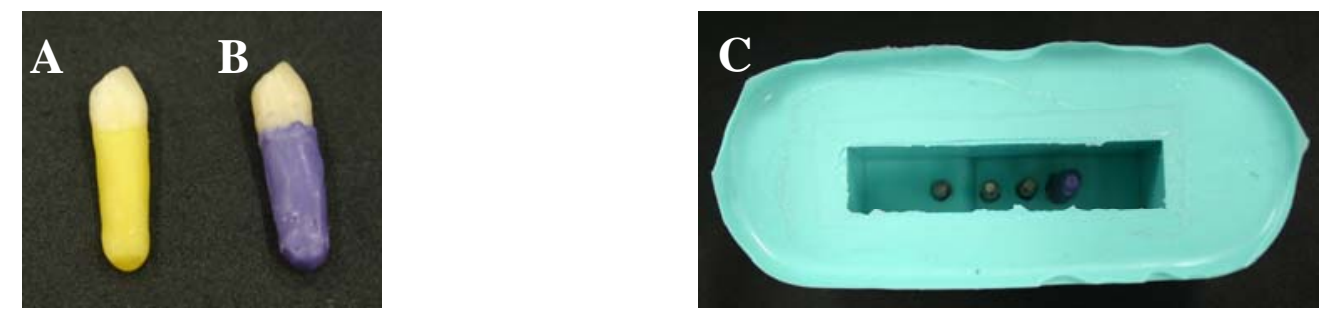

Figura 13. A - Réplica do primeiro pré-molar após imersão em cera. B - Réplica do primeiro pré-molar com ligamento periodontal confeccionado em Impregum. C - Molde de silicone com os implantes e o primeiro prémolar adaptados, previamente ao preenchimento com resina fotoelástica.

Resina fotoelástica do tipo Araldite GY279 e endurecedor Aradur 2963 (Huntsman, Everbeg, Bélgica), na proporção de $26 \mathrm{~mL}$ para $13 \mathrm{~mL}$, respectivamente, foram cuidadosamente manipulados (HARALDSON, 1980), evitando-se incorporação de bolhas; a mistura foi levada em seguida ao interior de uma câmara de vácuo durante 15 minutos para eliminação de pequenas bolhas resultantes da reação inicial entre os componentes da resina. Procedeu-se então, ao preenchimento da câmara do molde de silicone, incluindo assim, o dente e o implante no material fotoelástico (Figura 14). Foi aguardada a completa polimerização da resina à temperatura ambiente, em local fechado, durante 72 horas. Foram obtidos 4 modelos fotoelásticos, um para cada grupo avaliado. 

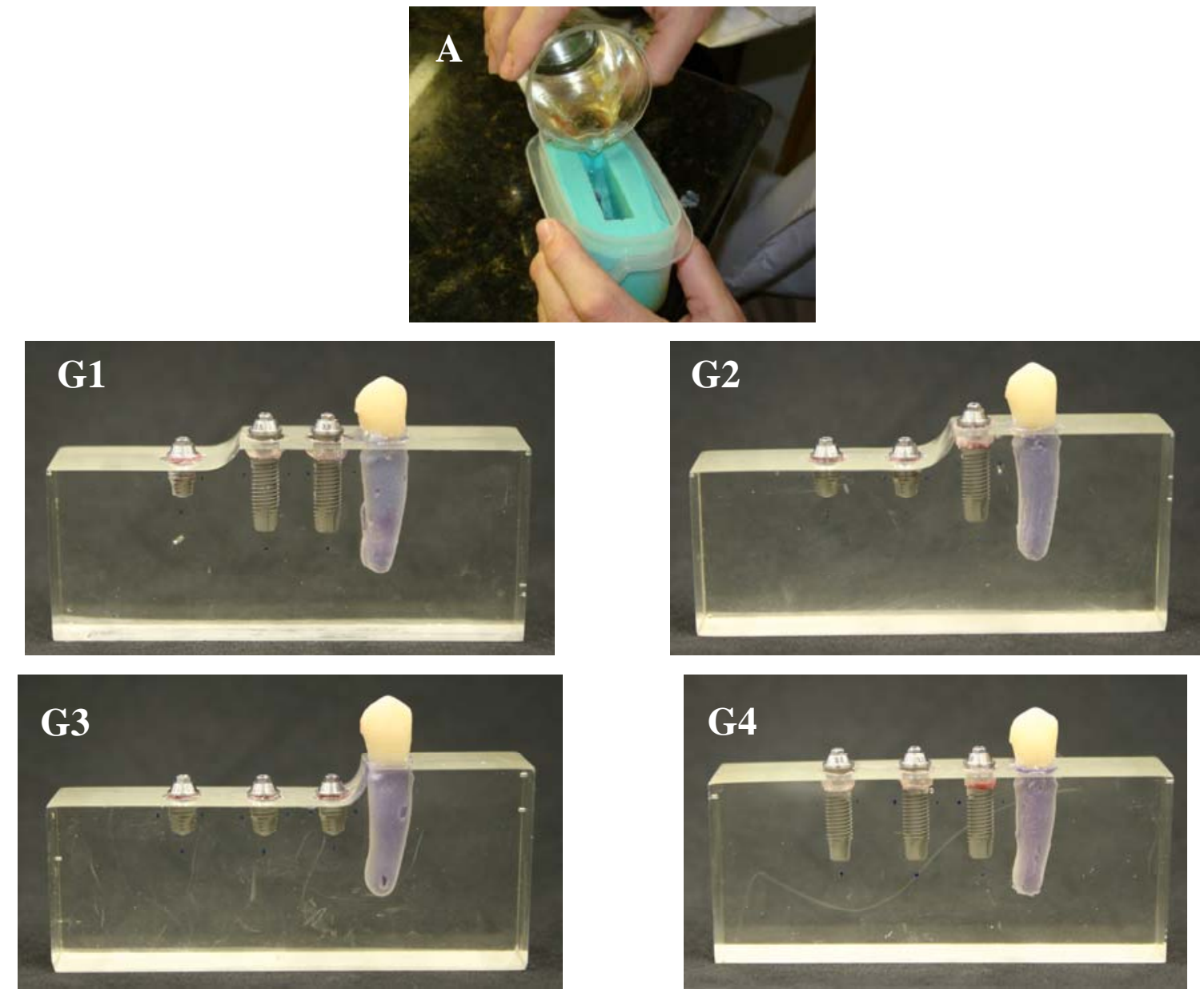

Figura 14. A - Preenchimento da câmara do molde de silicone Master com a resina fotoelástica. G1, G2, G3 e G4 - Modelos fotoelásticos obtidos.

\subsection{Análise fotoelástica}

Os modelos fotoelásticos assim obtidos foram levados ao polariscópio (OS - 100 Polamiter Systems / Strainoptics, In., North Wales, EUA) para realização das análises (Figura 15). Registros fotográficos de cada situação de interesse para análise foram realizados com auxílio de uma câmara digital (EOS Rebel, Canon, Tóquio, Japão) acoplada ao polariscópio. Um dispositivo para aplicação de cargas foi especialmente desenvolvido na Oficina Mecânica do Departamento de Materiais Dentários e Prótese - FORP/USP. O dispositivo composto por uma célula de carga de 50 Kgf (Kratos, São Paulo, Brasil) e um leitor de carga (IKE-01, 
Kratos) e diferentes modelos de pontas para aplicação de cargas foram acoplados ao polariscópio para viabilizar os ensaios.

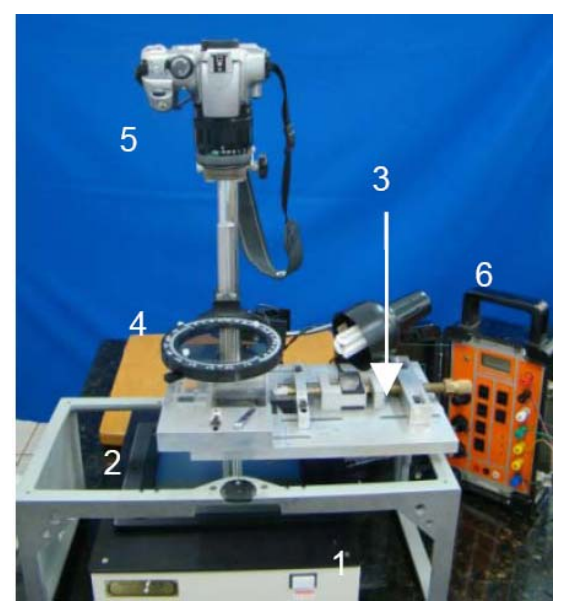

Figura 15. Polariscópio utilizado para análise qualitativa dos modelos fotoelásticos. 1- Fonte de luz; 2- Primeiro filtro polarizador; 3- Aplicador de carga; 4- Segundo filtro polarizador e analisador; 5- Máquina fotográfica; 6Leitor de carga.

Para análise qualitativa o polariscópio foi ajustado no modo de polarização circular. Foi observado o padrão de distribuição de franjas isocromáticas em torno dos implantes sob diferentes condições de aplicação de carga, onde quanto maior o número de franjas, maior a intensidade de tensão, e quanto mais próximas, maior a concentração dessas tensões. Assim, a franja de ordem $\mathrm{N}=0$ é visualizada na cor preta, a franja de ordem $\mathrm{N}=1$ é representada pela transição violeta-azul, a franja de ordem $\mathrm{N}=2$ encontra-se na transição vermelho-verde. A partir deste ponto, todas as franjas de número de ordem inteiro correspondem à transição vermelho-verde (Figura 16).

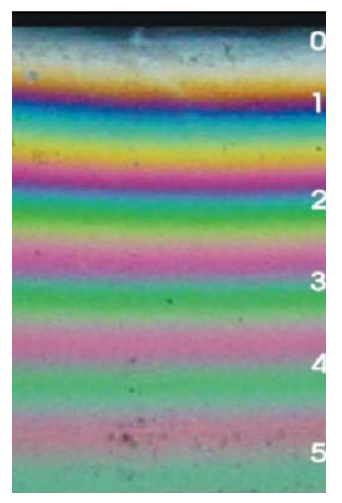

Figura 16. Ordens de franjas isocromáticas inteiras. 
Os modelos fotoelásticos obtidos foram levados ao polariscópio para certificação da ausência de franjas prévias à aplicação das cargas. A presença de franjas nessa fase indica que há tensões residuais no modelo, o qual, neste caso, foi colocado em estufa a $50^{\circ} \mathrm{C}$ por 10 minutos, para eliminação destas tensões, evitando interferências nos resultados, que poderiam comprometer a confiabilidade do método. Após a eliminação das tensões aguardou-se 10 minutos em temperatura de aproximadamente $23^{\circ} \mathrm{C}$ para o resfriamento do modelo antes da aplicação de carga.

Dois modelos de pontas de aplicação de carga foram utilizados para produzir três diferentes condições de carregamento na superfície oclusal das coroas: 1 - Puntiforme, obtido com uma ponta simples para carregamento no segundo pré-molar ou no segundo molar com $10 \mathrm{Kgf}$ ou $100 \mathrm{~N} ; 2$ - Oclusal distribuído - obtido por uma ponta que simulou a oclusão antagonista de cada um dos modelos com carga de $15 \mathrm{Kgf}$ ou $150 \mathrm{~N}$ (Figura 17). Os valores de carga foram determinados em ensaios piloto, visando não exceder o limite elástico do material fotoelástico e limitar a presença de franjas até as de $3^{\mathrm{a}}$ ordem, tornando a leitura dos dados mais simples e precisa.
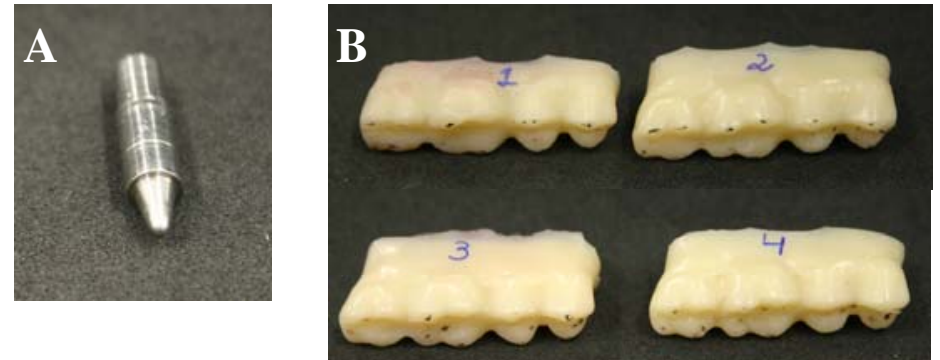

Figura 17. A - Aplicador pontual de carga. B - Aplicadores oclusais de carga 1, 2, 3 e 4, respectivamente para os modelos G1, G2, G3 e G4.

Para obtenção da ponta para carregamento oclusal distribuído foi encerada a superfície oclusal do segmento antagonista em relação ao enceramento inicial das coroas sobre o modelo mestre. Esse enceramento antagonista foi moldado com silicone (Zetalabor) e utilizado para obter quatro pontas do tipo oclusal distribuída em resina (Luxatemp), uma para cada modelo. 
Foi realizado ajuste oclusal no modelo mestre e no modelo fotoelástico antes das leituras, marcando os pontos de contato com carbono (AccuFilm II) até se obter a maior padronização possível dos pontos de contato oclusal entre a ponta e cada uma das próteses confeccionadas. Isto foi necessário para confirmar, refinar e garantir homogênea distribuição de cargas quando realizado o ensaio fotoelástico.

Após cada aplicação de carga o modelo fotoelástico foi novamente checado no polariscópio quanto à ausência total de franjas, e submetido ao relaxamento térmico das tensões como descrito anteriormente.

Aplicado o carregamento proposto foi feita a captura da imagem para posterior análise qualitativa, e em seguida foi realizada a análise quantitativa. Para a análise quantitativa o polariscópio foi ajustado para o modo de polarização plana, e foi acoplada ao conjunto uma lente de aumento de 10X (Nikon, Tóquio, Japão) (Figura 18).

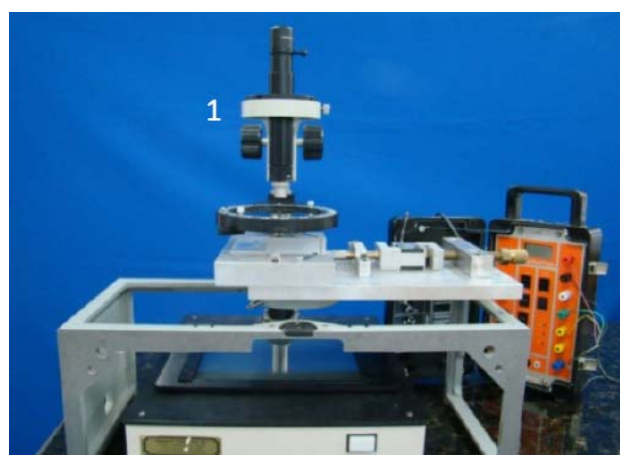

Figura 18. Polariscópio utilizado para análise quantitativa dos modelos fotoelásticos. 1- Lupa com filtro monocromático.

Foram analisados dois pontos na região cervical e um ponto na região apical de cada implante. Para reprodução exata do local dos pontos em cada modelo, os mesmos foram marcados no modelo fotoelástico com auxílio de transparência milimetrada e projetor de perfil (Projetor de Perfil modelo 6C, Nikon, Tóquio, Japão). As transparências foram colocadas em posição no modelo fotoelástico e foram realizadas perfurações nos pontos de 
interesse para posterior leitura de tensão. A Figura 19 ilustra a posição dos pontos de interesse que foram adotados neste estudo.

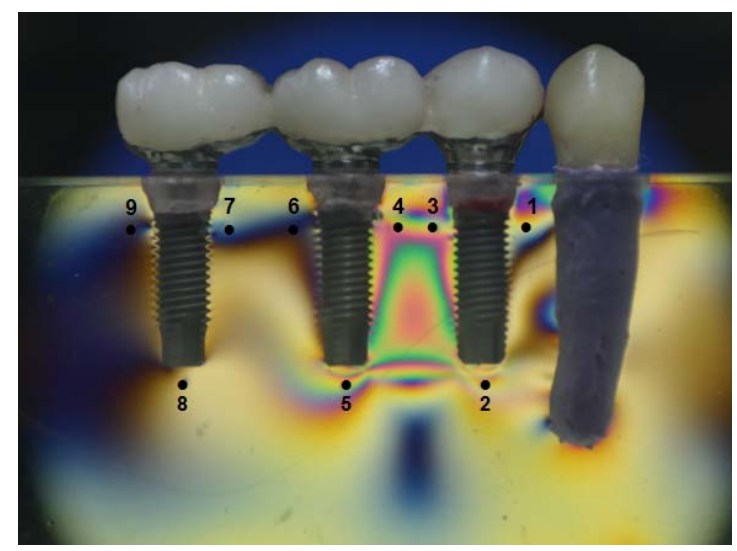

Figura 19. Localização dos pontos onde foram realizadas as quantificações das tensões.

Os valores de ordem de franja $(\eta)$ foram calculados em cada ponto por meio da leitura das ordens de franjas visualizadas no modelo fotoelástico, empregando o método de compensação de Tardy (NAGIB, 1999; MONTAROU; GAYLORD, 2004).

Para aplicar o método de Tardy, foi acoplada ao polariscópio uma lupa com aumento de $10 \mathrm{X}$, a qual possui um filtro monocromático que permite visualizar apenas as cores preta e amarela. A cor preta representa as franjas isoclínicas, e a cor amarela a região intermediária entre as franjas. $\mathrm{O}$ modelo fotoelástico foi posicionado entre os filtros polarizadores. $\mathrm{O}$ filtro analisador foi alinhado ao segundo filtro polarizador (Figura 20). Identificou-se o ponto a ser lido e entre quais ordens de franja ele se encontrava. Girou-se o suporte com o modelo no sentido horário, até que uma franja isoclínica ficasse posicionada sobre o ponto a ser analisado, tornando-o escuro. A partir desta posição, referida em graus na escala de suporte, o modelo foi totalmente girado em mais $45^{\circ}$ no sentido horário, e nessa posição o ponto tornouse totalmente claro. $\mathrm{O}$ disco analisador, representativo das frações de ordens de franja $(0,0 \mathrm{a}$ 1,0 ๆ), foi então girado no sentido horário até que uma franja isoclínica passasse novamente pelo ponto, tornando-o novamente escuro. Ao girar o analisador observou-se qual franja foi 
aproximada ao ponto para escurecê-lo. Como o ponto está localizado entre duas ordens de franjas, se a franja que se aproxima é a de maior ordem, o valor da fração medido na escala do analisador deve ser subtraído dessa franja. Ao contrário, se a que se aproxima é a de menor valor, o valor da fração medido na escala do analisador deve ser somado a esta menor franja. Este método permitiu localizar a exata ordem de franja para os pontos analisados.

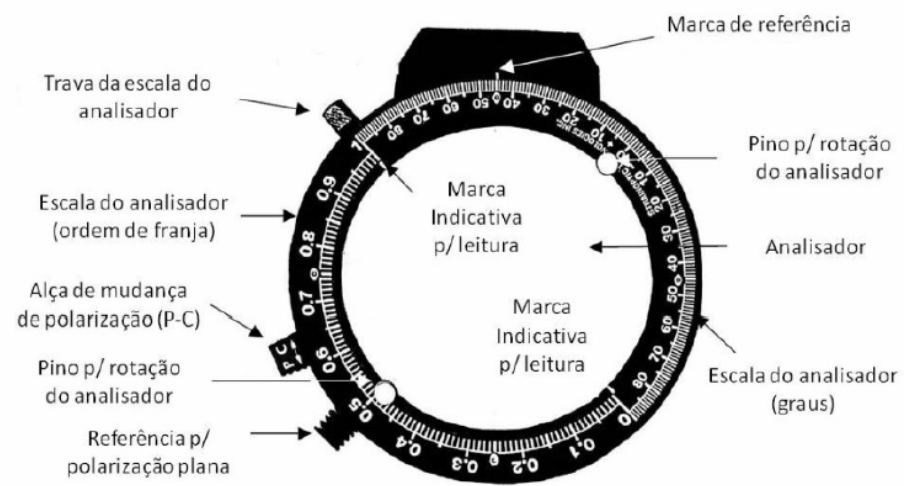

Figura 20. Analisador do polariscópio.

A constante óptica do material foi determinada através do teste de compressão diametral (Figura 21) conforme descrito por Bernardes (2004). Este teste foi realizado para a primeira manipulação de resina fotoelástica, obtendo assim o valor da constante óptica para esse lote (4,02 Brewsters).

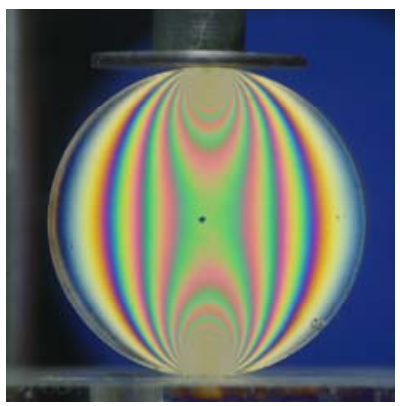

Figura 21. Teste de compressão diametral realizado no polariscópio. 
Conhecendo a espessura (b) dos modelos fotoelásticos em milímetros, a constante óptica $(\mathrm{K})$ da resina fotoelástica empregada no estudo em Brewsters, os valores de ordens de franja dos pontos estudados $(\eta)$ e o comprimento de ondas $(\lambda)$ para materiais plásticos (570nm), foi aplicada a equação da Lei óptica das tensões, obtendo-se assim os valores das tensões principais $(\sigma)$ em MPa para cada ponto.

Equação da Lei óptica das tensões.

$$
\sigma=\frac{\eta \cdot \lambda}{\text { b.K }}
$$

\subsection{Análise da proporção coroa/implante}

Para todos os modelos foram realizadas as medidas da proporção coroa/implante (C/I) de todos os implantes. Para tanto, altura das coroas foi medida com paquímetro digital (Mitutoyo). O cálculo da proporção C/I foi realizado de acordo com Blanes et al. (2007) que consideraram a proporção clínica como aquela entre a parte não implantada sobre a implantada. Dessa maneira, de acordo com a Figura 22, para os implantes curtos, A era a medida do comprimento da coroa acrescido da altura do Mini Pilar $(0,8 \mathrm{~mm})$ e B era o comprimento do implante $(5 \mathrm{~mm})$. Já para os implantes longos, A era a medida do comprimento da coroa acrescido da altura do Mini Pilar (3,5 mm), e B era o comprimento do implante $(11 \mathrm{~mm})$.

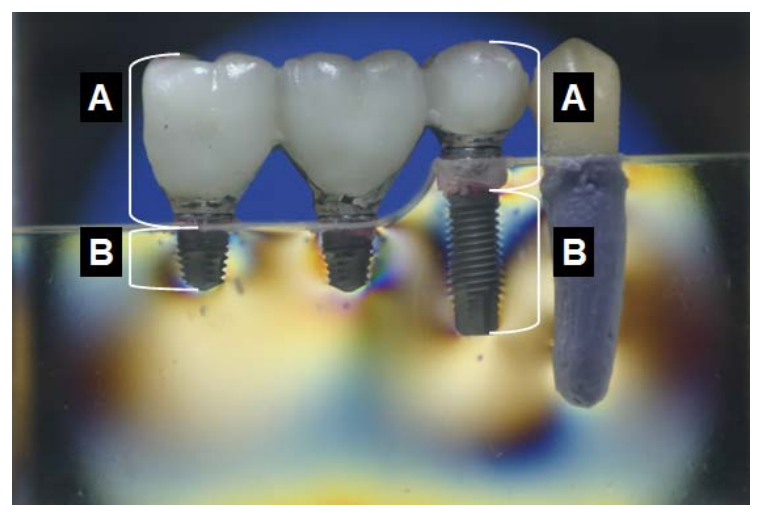

Figura 22. Realização da medida das alturas das coroas dos implantes curtos e longos, respectivamente. O esquema mostra a maneira como foi calculada a proporção C/I. 
RESULTADOS 


\section{RESULTADOS}

\subsection{Análise da passividade}

A Tabela 1 apresenta os resultados do teste de passividade para as próteses. O parafuso da coroa substituindo o segundo pré-molar foi apertado e as mensurações dos desajustes verticais foram realizadas nos três elementos suportados por implantes, sendo que as coroas do primeiro e segundo molares não foram parafusadas. No total, em cada elemento foram realizadas três medidas pela vestibular e também três medidas pela lingual, sendo utilizada a média desses valores. Em seguida, foi parafusado o segundo molar e tomadas as medidas dos desajustes da mesma maneira descrita anteriormente.

Tabela 1. Desajuste vertical $(\mu \mathrm{m})$ das coroas mensurado pelo teste de passividade com um dos parafusos da extremidade parafusado.

\begin{tabular}{cccc|ccc}
\hline & \multicolumn{2}{c|}{ Segundo pré-molar parafusado } & \multicolumn{3}{c}{ Segundo molar parafusado } \\
\cline { 2 - 7 } & $\mathbf{4 5}$ & $\mathbf{4 6}$ & $\mathbf{4 7}$ & $\mathbf{4 5}$ & $\mathbf{4 6}$ & $\mathbf{4 7}$ \\
\hline $\mathbf{G 1}$ & 23 & 98 & 91 & 93 & 94 & 47 \\
$\mathbf{G 2}$ & 20 & 33 & 51 & 35 & 18 & 43 \\
$\mathbf{G 3}$ & 37 & 60 & 93 & 89 & 91 & 76 \\
$\mathbf{G 4}$ & 5 & 38 & 66 & 41 & 4 & 15 \\
\hline
\end{tabular}

Pode-se verificar que os níveis de desajuste das coroas, em todos os grupos foram satisfatórios. 


\subsection{Análise fotoelástica qualitativa e quantitativa}

A Figura 23 mostra os modelos fotoelásticos posicionados no polariscópio, antes das próteses serem parafusadas sobre os mini-pilares. É importante destacar a ausência de tensões nos modelos.
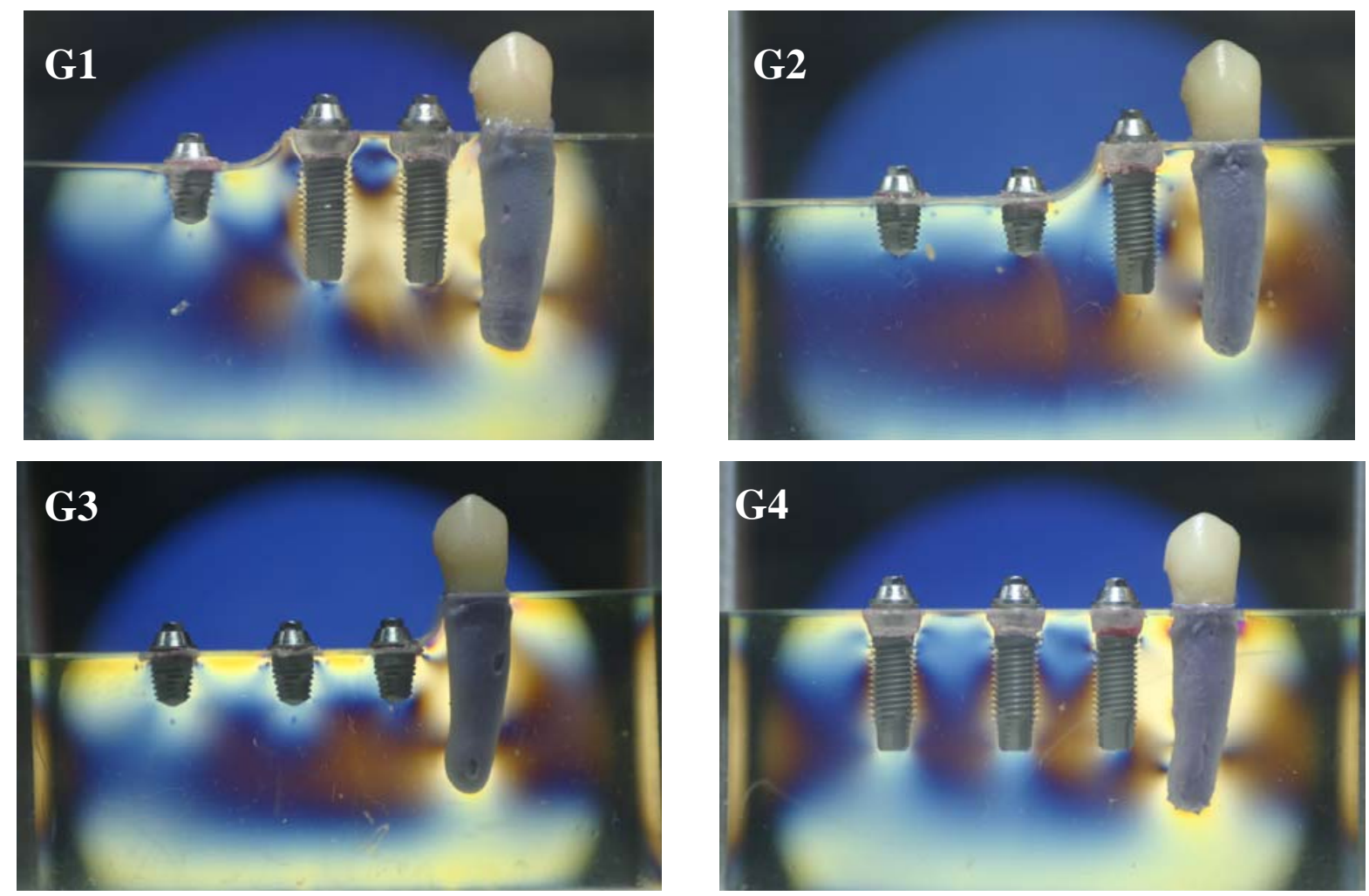

Figura 23. G1, G2, G3 e G4 - Modelos fotoelásticos com ausência de tensões antes da instalação das próteses.

A Figura 24 mostra os modelos fotoelásticos e a tensões a eles transmitidas após as próteses serem parafusadas, com torque indicado pelo fabricante (10 N.cm). A Tabela 2 mostra os valores quantificados (em MPa) das tensões transmitidas às regiões adjacentes aos implantes, para cada um dos pontos previamente selecionados. 

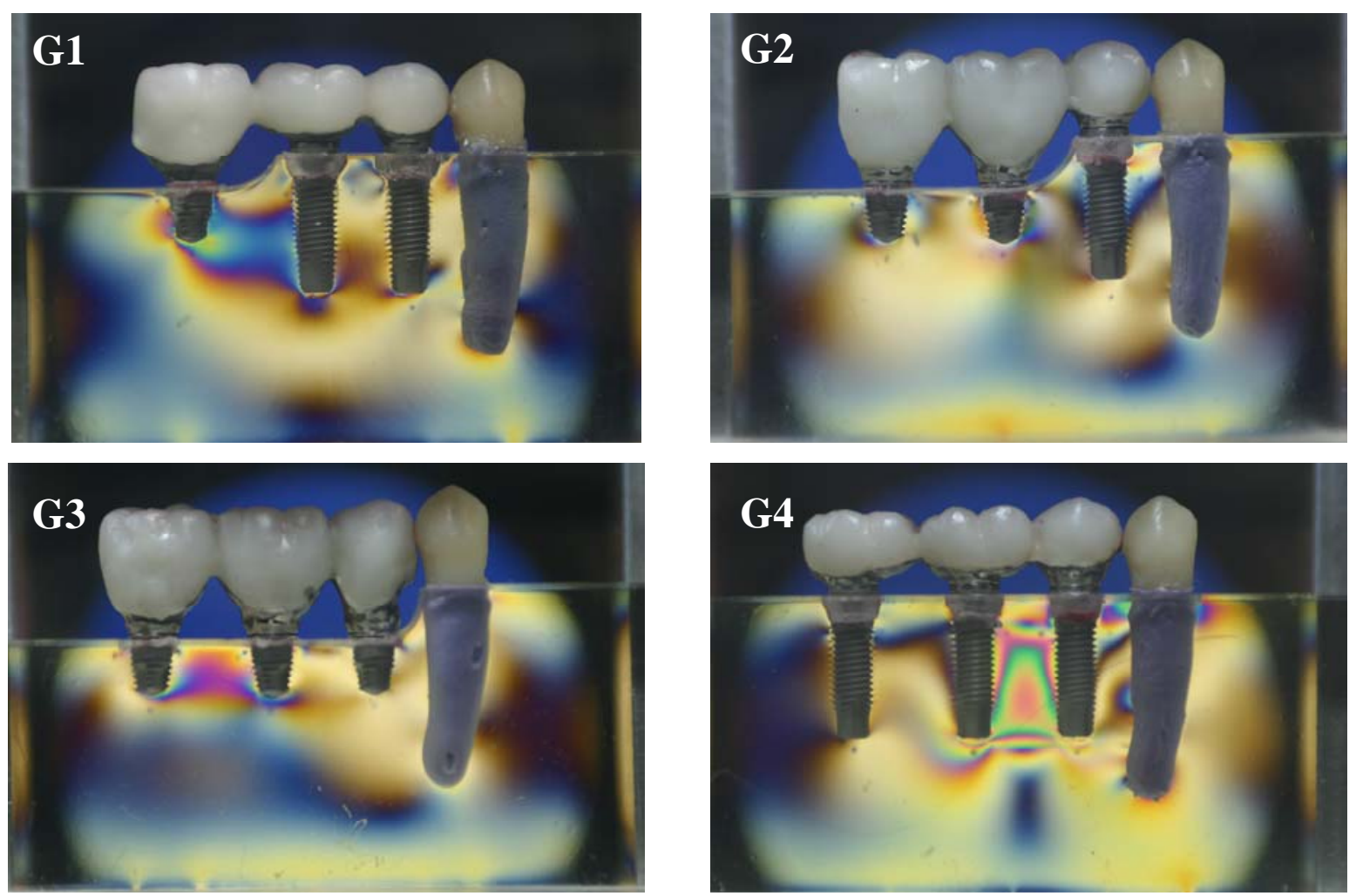

Figura 24. G1, G2, G3 e G4 - Tensões encontradas após as próteses serem parafusadas.

A análise qualitativa das tensões transmitidas aos modelos fotoelásticos revela, em todos os casos, em maior ou menor intensidade, a presença de tensões entre os implantes, tensões essas resultantes apenas do aperto dos parafusos.

Tabela 2. Tensões (MPa) medidas em cada um dos pontos, após as próteses serem parafusadas.

Somente a prótese

\begin{tabular}{c|c|c|c|c}
\hline \multirow{2}{*}{ Pontos de leitura } & Grupo 1 & Grupo 2 & Grupo 3 & Grupo 4 \\
\cline { 2 - 5 } & Tensão (MPa) & Tensão (MPa) & Tensão (MPa) & Tensão (MPa) \\
\hline $\mathbf{1}$ & 7,65 & 2,46 & 3,31 & 2,98 \\
$\mathbf{2}$ & 4,54 & 2,93 & 0,48 & 12,57 \\
$\mathbf{3}$ & 2,74 & 2,46 & 2,88 & 14,74 \\
$\mathbf{4}$ & 3,54 & 7,28 & 5,58 & 14,65 \\
$\mathbf{5}$ & 8,03 & 12,1 & 6,85 & 15,97 \\
$\mathbf{6}$ & 5,20 & 0,85 & 6,99 & 0 \\
$\mathbf{7}$ & 6,71 & 3,69 & 6,61 & 3,12 \\
$\mathbf{8}$ & 13,14 & 2,08 & 7,18 & 5,48 \\
$\mathbf{9}$ & 5,10 & 3,50 & 5,06 & 1,98 \\
\hline TOTAL & 56,65 & 37,35 & 44,94 & 71,49 \\
\hline
\end{tabular}


A quantificação das tensões corrobora a análise qualitativa, revelando os maiores valores para os implantes correspondentes aos dentes 45 e 46 do G4. Foi observado também que o G4 foi o grupo que apresentou maior transmissão de tensões para áreas adjacentes aos implantes (71,49 MPa).

A Figura 25 mostra os modelos fotoelásticos e a tensões a eles transmitidas após as próteses serem submetidas à aplicação de $150 \mathrm{~N}$ de carga na forma de contato oclusal distribuído. A Tabela 3 mostra os valores, em MPa, das tensões transmitidas nas regiões adjacentes aos implantes, para os pontos previamente selecionados.
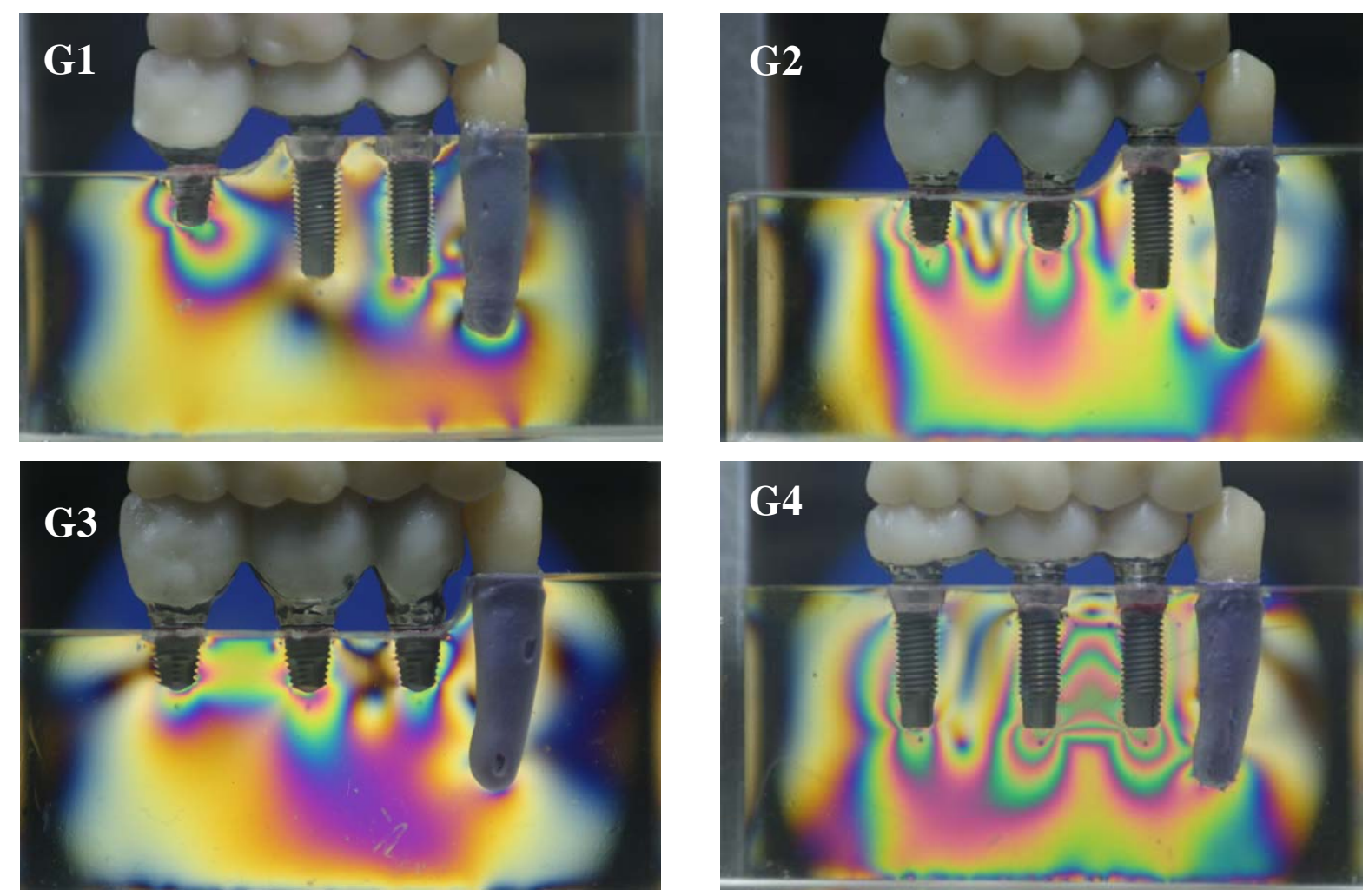

Figura 25. Tensões observadas após a aplicação de carga oclusal distribuída (150 N). 
A análise qualitativa da distribuição de tensões adjacentes aos implantes revela, para todos os grupos, participação do pré-molar na distribuição dessas tensões. Ainda, o G3 foi o grupo com menor transferência de tensões para a região distal do implante correspondente ao 47. A análise mostra também maior concentração de tensões para o modelo fotoelástico do G4.

Tabela 3. Tensões (MPa) medidas em cada um dos pontos, após a aplicação de carga oclusal distribuída (150 $\mathrm{N})$.

\section{Carga oclusal distribuída (150 N)}

\begin{tabular}{c|c|c|c|c}
\hline \multirow{2}{*}{$\begin{array}{c}\text { Pontos de } \\
\text { leitura }\end{array}$} & Grupo 1 & Grupo 2 & Grupo 3 & Grupo 4 \\
\cline { 2 - 5 } & Tensão (MPa) & Tensão (MPa) & Tensão (MPa) & Tensão (MPa) \\
\hline $\mathbf{1}$ & 11,15 & 6,62 & 13,7 & 17,86 \\
$\mathbf{2}$ & 18,52 & 16,82 & 12,76 & 30,62 \\
$\mathbf{3}$ & 6,52 & 6,99 & 4,39 & 16,73 \\
$\mathbf{4}$ & 0 & 12,14 & 5,67 & 18,90 \\
$\mathbf{5}$ & 1,8 & 29,06 & 26,27 & 31,00 \\
$\mathbf{6}$ & 3,31 & 9,45 & 23,34 & 3,87 \\
$\mathbf{7}$ & 6,95 & 5,01 & 15,69 & 6,05 \\
$\mathbf{8}$ & 23,25 & 24,85 & 17,2 & 26,60 \\
$\mathbf{9}$ & 13,23 & 25,42 & 7,75 & 13,09 \\
\hline TOTAL & 84,73 & 136,36 & 126,77 & 164,72 \\
\hline
\end{tabular}

A análise quantitativa corrobora a qualitativa, com os maiores valores para o modelo do G4 (183,62 MPa). Também é possível perceber que o menor valor de tensão na região distal do 47 corresponde ao modelo fotoelástico do G3.

A Figura 26 mostra os modelos fotoelásticos e a tensões a eles transmitidas após as próteses serem submetidas à aplicação de contato pontual de $100 \mathrm{~N}$ na mesial do 45 . A Tabela 4 mostra os valores, em MPa, das tensões transmitidas nas regiões adjacentes aos implantes, para os pontos previamente selecionados. 

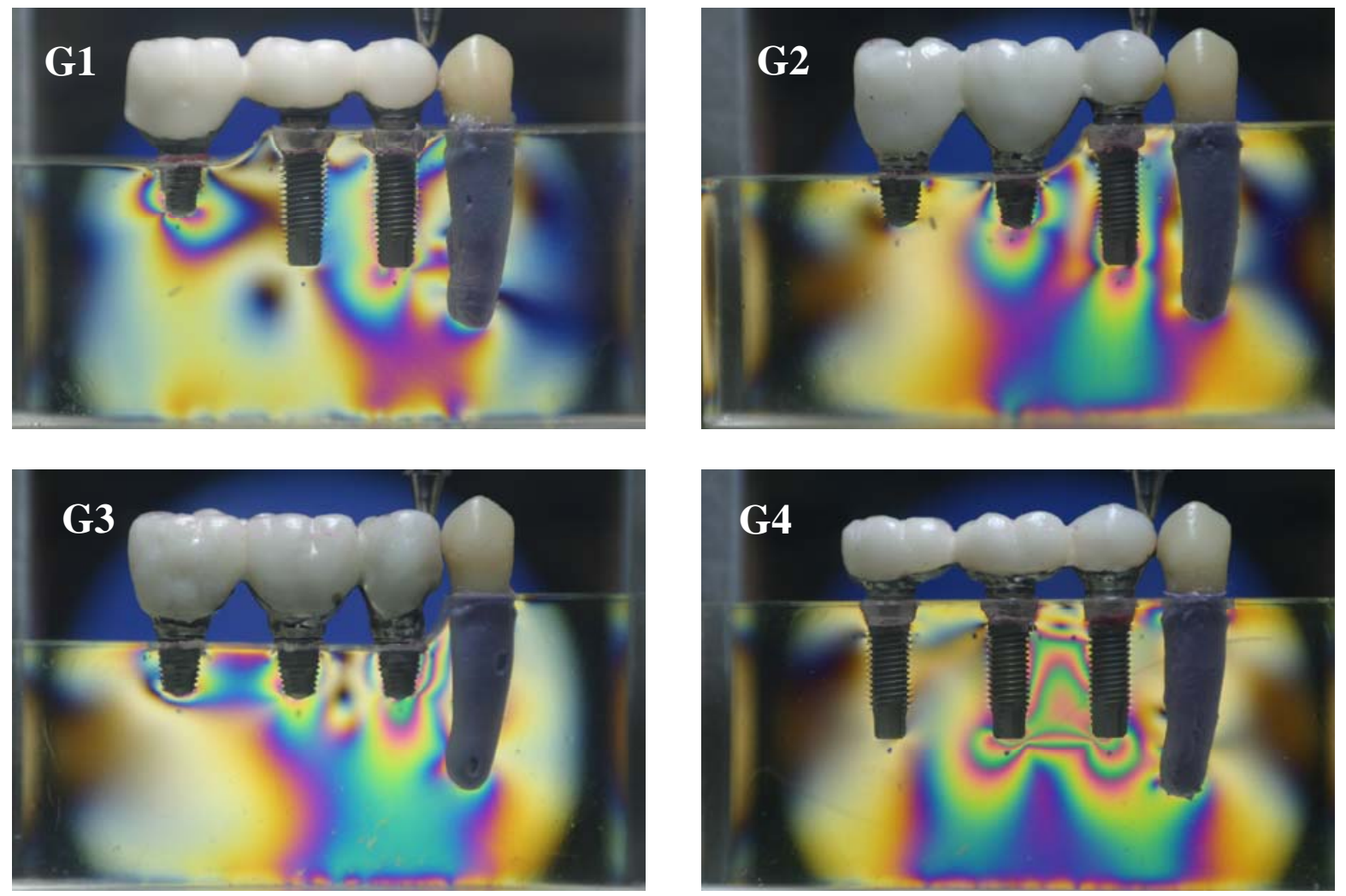

Figura 26. Tensões observadas após a aplicação de carga pontual na mesial do segundo pré-molar (100 N).

Após aplicação de carga na mesial do 45, a análise qualitativa revela a presença de tensões transmitidas ao implante mais próximo da aplicação da carga (implantes da região do 45). Nos modelos em que há implantes curtos, percebe-se também a transmissão de tensões ao implante curto mais próximo da aplicação da carga (G1, G2 e G3). Ainda, em todos os casos, houve participação do pré-molar na transferência de tensões aos modelos, sempre com tensões presentes na apical. 
Tabela 4. Tensões (MPa) medidas em cada um dos pontos, após a aplicação de carga de $100 \mathrm{~N}$ na mesial do 45.

\section{Contato Pontual na Mesial do 45}

\begin{tabular}{c|c|c|c|c}
\hline \multirow{2}{*}{$\begin{array}{c}\text { Pontos de } \\
\text { leitura }\end{array}$} & Grupo 1 & Grupo 2 & Grupo 3 & Grupo 4 \\
\cline { 2 - 5 } & Tensão (MPa) & Tensão (MPa) & Tensão (MPa) & Tensão (MPa) \\
\hline $\mathbf{1}$ & 11,15 & 9,45 & 15,12 & 12,76 \\
$\mathbf{2}$ & 25,42 & 19,70 & 21,17 & 30,05 \\
$\mathbf{3}$ & 9,45 & 4,30 & 4,91 & 17,01 \\
$\mathbf{4}$ & 11,43 & 4,16 & 0 & 18,9 \\
$\mathbf{5}$ & 5,1 & 20,46 & 15,97 & 25,51 \\
$\mathbf{6}$ & 2,74 & 5,67 & 12,38 & 2,83 \\
$\mathbf{7}$ & 4,16 & 3,60 & 9,45 & 3,69 \\
$\mathbf{8}$ & 14,65 & 1,70 & 6,52 & 6,9 \\
$\mathbf{9}$ & 7,56 & 1,89 & 7,56 & 2,17 \\
\hline TOTAL & 91,66 & 70,93 & 93,08 & 119,82 \\
\hline
\end{tabular}

A análise quantitativa mostrou maiores valores de tensões para o modelo do G4 (119,82 MPa). Ainda, os maiores valores em todos os grupos foram para os pontos localizados na região apical dos dois primeiros implantes, sendo que para G1, G3 e G4 as maiores tensões foram para os implantes da região do 45, respectivamente 25,42 MPa; 21,17 MPa e 30,05 MPa, e para o G2 os maiores valores de tensões foram encontrados na apical do implante da região do 46 (20,46 MPa).

A Figura 27 mostra os modelos fotoelásticos e a tensões a eles transmitidas após as próteses serem submetidas à aplicação de contato pontual de $100 \mathrm{~N}$ de carga na distal do 47. A Tabela 5 mostra os valores, em MPa, das tensões transmitidas nas regiões adjacentes aos implantes, para os pontos previamente selecionados. 

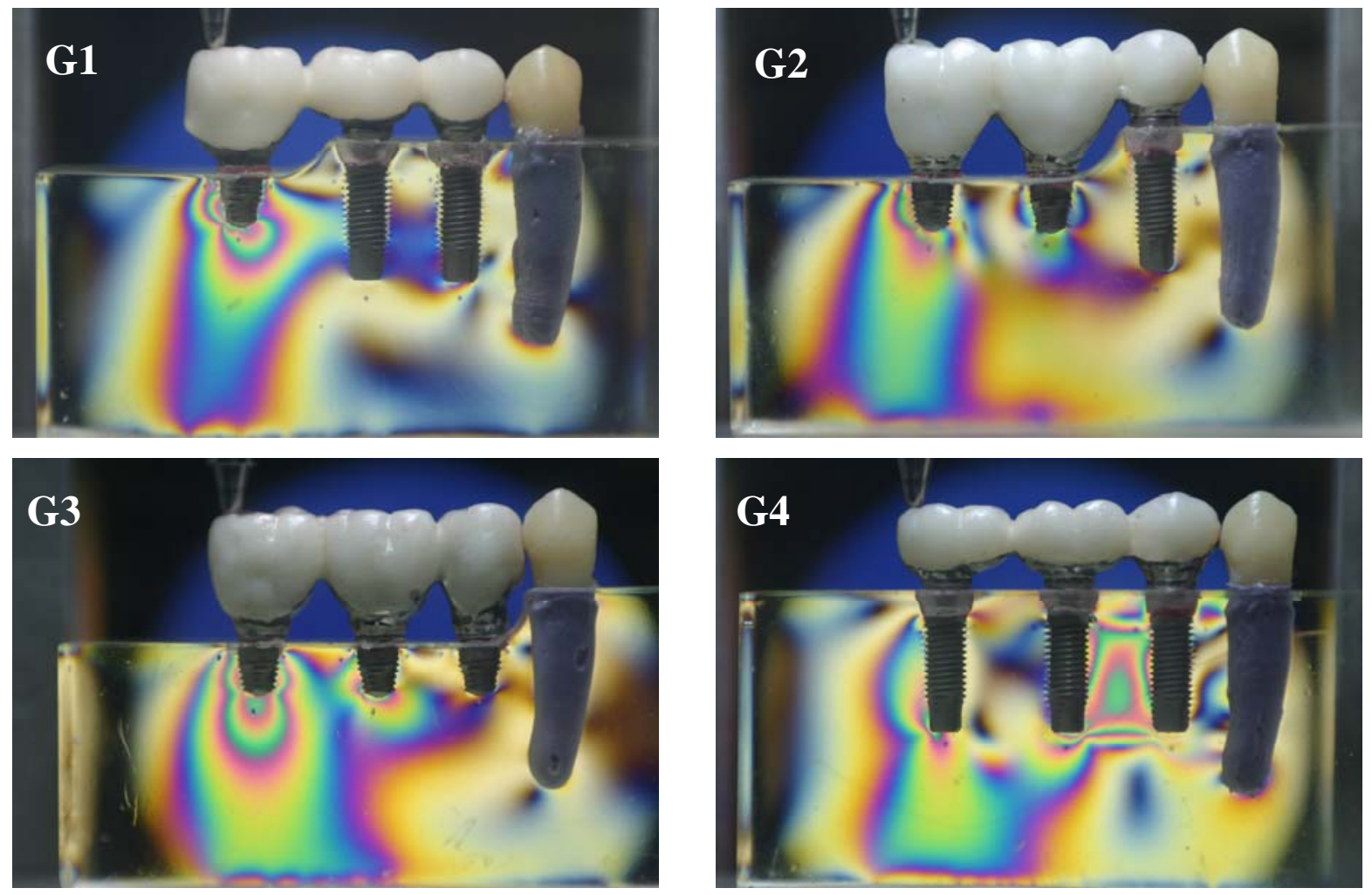

Figura 27. Tensões observadas após a aplicação de carga pontual na distal do 47 (100 N).

À semelhança da situação anterior, houve concentração de tensões no implante mais próximo à aplicação de carga (implante da região do 47). Em todos os casos, tensões foram geradas na região distal do 47 e embora o pré-molar também participasse na distribuição de tensões, nesse caso, elas são menores e não há tensões na apical. Mais uma vez, é possível perceber maior concentração de tensões no modelo do G4. 
Tabela 5. Tensões (MPa) medidas em cada um dos pontos, após a aplicação de carga de $100 \mathrm{~N}$ na distal do 47.

\section{Contato Pontual na Distal do 47}

\begin{tabular}{c|c|c|c|c}
\hline \multirow{2}{*}{$\begin{array}{c}\text { Pontos de } \\
\text { leitura }\end{array}$} & Grupo 1 & Grupo 2 & Grupo 3 & Grupo 4 \\
\cline { 2 - 5 } & Tensão (MPa) & Tensão (MPa) & Tensão (MPa) & Tensão (MPa) \\
\hline $\mathbf{1}$ & 7,28 & 0,00 & 0,00 & 3,50 \\
$\mathbf{3}$ & 4,72 & 7,32 & 9,45 & 14,84 \\
$\mathbf{4}$ & 3,78 & 5,29 & 4,54 & 17,20 \\
$\mathbf{5}$ & 4,54 & 9,45 & 3,78 & 27,03 \\
$\mathbf{6}$ & 4,44 & 13,94 & 13,84 & 20,98 \\
$\mathbf{7}$ & 4,63 & 9,45 & 9,45 & 0,57 \\
$\mathbf{8}$ & 4,35 & 0,00 & 11,34 & 3,69 \\
$\mathbf{9}$ & 24,95 & 12,95 & 27,69 & 17,01 \\
\hline TOTAL & 16,54 & 12,47 & 13,70 & 12,76 \\
\hline
\end{tabular}

Pela análise quantitativa percebe-se que em todas as situações houve tensões presentes na região distal do 47. Mais uma vez, a maior concentração de tensões foi no modelo do G4 $(117,56 \mathrm{MPa})$.

A Tabela 6 mostra os valores de tensões (MPa) transmitidos ao redor de cada implante, para cada uma das situações avaliadas e a Tabela 7 mostra os valores de tensões presentes na região cervical dos implantes, também para cada uma das situações.

Tabela 6. Tensões (MPa) medidas em cada implante, para cada uma das situações simuladas.

\begin{tabular}{|c|c|c|c|c|c|c|c|c|c|c|c|c|}
\hline & \multicolumn{3}{|c|}{ Só a Prótese } & \multicolumn{3}{|c|}{$\begin{array}{l}\text { Oclusal Distribuída } \\
\qquad(150 \mathrm{~N})\end{array}$} & \multicolumn{3}{|c|}{$\begin{array}{c}\text { Pontual Mesial } \\
\qquad(100 \mathrm{~N})\end{array}$} & \multicolumn{3}{|c|}{$\begin{array}{c}\text { Pontual Distal } \\
\text { (100 N) }\end{array}$} \\
\hline & 45 & 46 & 47 & 45 & 46 & 47 & 45 & 46 & 47 & 45 & 46 & 47 \\
\hline G1 & 14,93 & 16,77 & 24,95 & 36,19 & 5,11 & 43,43 & 46,02 & 19,27 & 26,37 & 15,79 & 13,61 & 45,84 \\
\hline G2 & 7,84 & 20,22 & 9,26 & 30,43 & 50,65 & 55,28 & 33,45 & 30,29 & 7,19 & 12,61 & 32,84 & 25,42 \\
\hline G3 & 6,66 & 19,42 & 18,85 & 30,85 & 55,28 & 40,82 & 41,20 & 28,35 & 23,53 & 13,99 & 27,07 & 52,73 \\
\hline G4 & 30,29 & 30,62 & 10,58 & 65,21 & 53,77 & 45,74 & 59,82 & 47,25 & 12,76 & 35,54 & 48,58 & 33,46 \\
\hline
\end{tabular}


Para todas as situações simuladas, os maiores valores de tensões para o implante da região do 45 foram encontrados no modelo fotoelástico do G4. O mesmo ocorreu para o implante da região do 46, à exceção quando foi aplicada carga de $150 \mathrm{~N}$ sob a forma de contato oclusal distribuído, em que o maior valor de tensão foi encontrado no modelo do G3. Para o implante mais posterior (região do 47), em nenhuma das situações avaliadas os modelos do G2 e do G4 apresentaram os maiores valores, que foram ou para o G1 (só a prótese e contato pontual na mesial do 45) ou para o G3 (contato oclusal distribuído e contato pontual na distal do 47).

Tabela7. Tensões (MPa) medidas na cervical de cada implante, para cada uma das situações simuladas.

\begin{tabular}{|c|c|c|c|c|c|c|c|c|c|c|c|c|}
\hline & \multicolumn{3}{|c|}{ Só a Prótese } & \multicolumn{3}{|c|}{$\begin{array}{l}\text { Oclusal Distribuída } \\
\qquad(150 \mathrm{~N})\end{array}$} & \multicolumn{3}{|c|}{$\begin{array}{c}\text { Pontual Mesial } \\
\qquad(100 \mathrm{~N})\end{array}$} & \multicolumn{3}{|c|}{$\begin{array}{c}\text { Pontual Distal } \\
\qquad(100 \mathrm{~N})\end{array}$} \\
\hline & 45 & 46 & 47 & 45 & 46 & 47 & 45 & 46 & 47 & 45 & 46 & 47 \\
\hline G1 & 10,40 & 8,74 & 11,81 & 17,67 & 3,31 & 20,18 & 20,60 & 14,17 & 11,72 & 11,06 & 9,17 & 20,89 \\
\hline G2 & 4,91 & 8,13 & 7,18 & 13,61 & 21,59 & 30,43 & 13,75 & 9,83 & 5,49 & 5,29 & 18,90 & 12,47 \\
\hline G3 & 6,19 & 12,57 & 11,67 & 18,09 & 29,01 & 23,62 & 20,03 & 12,38 & 17,01 & 4,54 & 13,23 & 25,04 \\
\hline G4 & 17,72 & 14,65 & 5,10 & 34,59 & 22,77 & 19,14 & 29,77 & 21,74 & 5,86 & 20,70 & 27,60 & 16,45 \\
\hline
\end{tabular}

De acordo com a Tabela 7, o implante correspondente à região do 45 em que houve maior concentração de tensões foi para o modelo do G4 quando submetido à carga oclusal distribuída. Para o implante da região do 46, a carga oclusal distribuída também transmitiu mais tensão a esse implante, contudo o maior valor foi encontrado para o modelo do G3. Para o implante mais distal, da região do 47, a carga oclusal distribuída também transmitiu mais tensão a esse implante, contudo o maior valor foi encontrado para o modelo do G2. 


\subsection{Análise da proporção coroa/implante}

Quanto à proporção coroa/implante, pode-se perceber (Tabela 8) que a metodologia anteriormente descrita para padronizar as dimensões das coras foi efetiva, com discrepâncias pequenas entre si. Ainda, de posse desses valores, pode-se perceber que para os implantes curtos, em todos os casos as coroas foram proporcionalmente 2,5 vezes maiores que os implantes. Já para os implantes longos, a proporção da altura das coroas quando comparadas aos implantes girou em torno de 1.

Tabela 8. Media e Desvio Padrão das proporções coroa/implante para os implantes de todos os grupos.

\begin{tabular}{c|c|c}
\hline & Implantes Curtos & Implantes Longos \\
\hline Média & 2,63 & 1,02 \\
\hline Desvio Padrão & 0,10 & 0,04 \\
\hline
\end{tabular}


DISCUSSÃO 


\section{DISCUSSÃO}

A necessidade de confecção de próteses fixas sobre múltiplos implantes adjacentes é hoje uma realidade e sabe-se que a passividade dessas próteses é considerada quesito importante, que influencia diretamente o sucesso e a manutenção da osseointegração (GUICHET et al., 2002). Vários autores afirmam que próteses não passivas sobre o sistema de suporte promovem, de maneira direta, formação de tensões no tecido perimplantar (MISCH, 2000; MENANI et al., 2011; TORRES et al., 2011). Alguns autores recomendam inclusive a utilização de próteses unitárias em detrimentos das ferulizadas (SOLNIT e SCHNEIDER, 1998) com a intenção de obter próteses mais passivas. Todavia, diferentes estudos mostram que próteses sobre implantes unidas promovem melhor distribuição de tensões na região interimplantar quando comparadas com próteses unitárias (MISCH et al., 2006; ANITUA et al., 2010; MENANI et al., 2011; TIOSSI et al., 2011) e a utilização de solda a laser é uma maneira eficaz de se conseguir próteses fixas sobre múltiplos implantes com desajustes verticais reduzidos (MENANI et al., 2011; TIOSSI et al., 2011).

Clinicamente, entretanto, não existe uma maneia simplificada de se avaliar a adaptação das próteses sobre os intermediários (SAHIN; ÇEHRELI, 2001; KARL et al., 2006). No presente estudo, foi apertado o parafuso de uma extremidade e verificada a desadaptação das outras duas coroas (APARÍCIO, 1994), o que resultou em valores, para todos os casos, menores que $100 \mu \mathrm{m}$, considerados clinicamente aceitáveis (JEMT; LEKHOLM, 1993).

Além da verificação do desajuste das coroas em microscópio, após serem parafusados os três elementos, cada grupo foi submetido à análise fotoelástica. A análise fotoelástica vem sendo utilizada em pesquisas que estudam a distribuição de tensão ao redor de implantes desde 1980 (HARALDSON, 1980). Essa técnica possibilita que tensões geradas em uma resina que apresenta característica fotoelástica possam ser visualizadas pelo padrão de distribuição da luz nesse material (MENANI et al., 2011; TORRES et al., 2011). Contudo, 
sabe-se que a análise qualitativa da distribuição de tensões é subjetiva, sendo que a combinação da fotoelasticidade com fórmulas matemáticas pelo método de compensação de Tardy faz com que seja possível quantificar os valores de tensão $(\tau)$ em determinada região (BERNARDES et al., 2009). Esse método foi utilizado no presente trabalho, para que fosse possível quantificar de que maneira tensões geradas pelas próteses e cargas a elas aplicadas, seriam transmitidas aos implantes, que por sua vez transmitiriam tensões à resina fotoelástica.

Mesmo os valores para a desadaptação em próteses parafusadas sendo aceitáveis clinicamente, por menores que sejam, o simples aperto dos parafusos, à medida que diminuem o desajuste vertical, provocam tensões no sistema de suporte interimplantar (GUICHET et al., 2000; KARL et al., 2006). Esses autores corroboram o que foi encontrado no presente estudo, que revela a presença de tensões em todos os modelos após as próteses serem parafusadas, tanto pela análise fotoelástica qualitativa (Figura 24) quanto quantitativa (Tabelas 2 e 5), pelas quais se percebem valores que variam bastante, com tensões quantificadas de 6,66 até 30,62 MPa por implante. É interessante ressaltar que no presente trabalho não houve correlação direta entre desajuste vertical e concentração de tensões, ou seja, os maiores desajustes foram encontrados para o modelo do G1 e a maior tensão para o modelo do G4 (Tabelas 2 e 5). Esses achados estão de acordo com os de vários autores (GUICHET et al., 2000; TORRES et al., 2011), que não encontraram relação direta entre desajuste vertical e concentração de tensões ao redor dos implantes.

As análises qualitativa e quantitativa (Figura 24 e Tabela 2, respectivamente) mostraram que, após o aperto dos parafusos com torque recomendado pelo fabricante de 10 N.cm, as tensões geradas pelo desajuste das próteses foram maiores no modelo do G4, em que foram utilizados três implantes longos, e menores no modelo do G3, em que havia três implantes curtos. Pierrisnard e cols. (2003) também obtiveram maiores tensões transmitidas à região interimplantar para implantes longos $(12 \mathrm{~mm})$, quando comparados com implantes 
curtos $(6 \mathrm{~mm})$. Pelo método de elementos finitos, os pesquisadores encontraram que quanto maior o implante, maior a tensão em sua estrutura e também maior tensão transmitida ao tecido ósseo. Os autores justificam seus achados afirmando que, sob mesma tensão, implantes curtos podem se mover e girar um pouco, causando pequena deformação óssea, o que não acontece com implantes longos, que transmitiriam maior carga à região interimplantar devido à sua maior rigidez.

A tensão transmitida ao redor dos implantes também foi avaliada após ser aplicada carga oclusal distribuída de $150 \mathrm{~N}$ sobre as próteses. Pela Figura 25 e Tabelas 3 e 6 pode-se perceber que houve participação dos três implantes e do primeiro pré-molar na distribuição de tensão em todos os modelos avaliados. Esses resultados estão de acordo com os de Menani et al. (2011) que mostraram em recente trabalho, também pelo método fotoelástico, participação tanto dos dentes simulados no estudo (primeiro pré-molar e segundo molar) quanto dos dois implantes instalados entre esses dentes, quando carga oclusal balanceada é aplicada sobre as coroas. Os resultados do presente trabalho revelam a importância do contato proximal efetivo (GUICHET et al., 2002) e também do ajuste oclusal antagonista realizado de maneira criteriosa para que implantes não sejam sobrecarregados (APARÍCIO, 1994; MISCH et al., 2005; RAVIV et l., 2010), o que poderia implicar em fratura do parafuso do intermediário, fratura do implante, reabsorção óssea cervical e até perda da osseointegração (RANGERT et al., 1995; GOODACRE et al., 2003; MISCH et al., 2005). Ainda, nos grupos em que havia implantes longos e curtos (G1 e G2), pode-se perceber que, comparativamente, os implantes curtos transmitiram mais tensão à região interimplantar que os longos (Tabela 6). Foi observado também, que a aplicação da carga oclusal distribuída resultou em maior concentração de tensões exatamente onde elas já estavam presentes quando do aperto dos parafusos, ou seja, o modelo do G4 foi o que apresentou maior concentração de tensão (Figura 25 e Tabela 3), o que reforça a importância da passividade de próteses parafusadas. 
A aplicação da carga pontual de $100 \mathrm{~N}$ na mesial do segundo pré-molar mostrou, para todos os grupos, que a maior quantidade de tensões esteve justamente ao redor do implante mais próximo à região de incidência da carga, ou seja, independente do implante utilizado ser longo ou curto, a região ao redor do implante correspondente ao dente 45 foi a que apresentou maiores valores de tensões (Figura 26 e Tabela 6). Esses resultados estão de acordo aos de Guichet et al., 2002 e Menani et al., 2011, que também comprovaram, à semelhança desse presente estudo, a participação dos demais implantes utilizados na reabilitação, o que mostra uma grande vantagem das próteses ferulizadas, ou seja, a tensão, mesmo que aplicada de maneira pontual, localizada, não recai apenas sobre a região de aplicação.

A carga pontual aplicada na distal do 47 , contudo, não transmitiu tensões semelhantes àquela aplicada na mesial do 45, aos implantes de todas as situações avaliadas. Para os grupos com um implante curto (G1) e com três implantes curtos (G3), a concentração de tensão foi concentrada ao redor do implante mais próximo à aplicação de carga, ou seja, os maiores valores de tensões foram encontrados na região adjacente ao implante mais distal, o que substitui o dente 47 (Figura 27 e Tabela 6). Assim, esses grupos se comportaram de maneira semelhante àquela quando aplicada carga na mesial do 45 .

Já os modelos do G2 e do G4, ou seja, os modelos com dois e nenhum implante curto, respectivamente, se comportaram de maneira diferente quando aplicada carga na região distal do 47. Para esses dois modelos, as maiores tensões foram encontradas adjacentes ao implante da região do 46, justamente onde o torque de instalação e o desajuste da prótese provocou maior tensão. É importante ressaltar que para o G2 o implante da região 46 é um implante curto, e para o G4, é um implante longo. Assim, percebe-se que o semelhante padrão de distribuição de tensão ocorrido nesses dois casos foi independente do comprimento do implante, e quando aplicada carga na região de extremidade livre, exatamente oposta ao contato proximal dental simulado (primeiro pré-molar), as tensões tenderam a ser maiores ao 
redor do implante onde o aperto do parafuso para instalação da prótese promoveu maior tensão (Tabela 6).

No presente trabalho, quando comparadas as duas cargas pontuais aplicadas, simulando contato oclusal prematuro na mesial do 45 ou na distal do 47 , percebe-se que se o contato é localizado na região do implante mais próximo ao dente, a tensão transmitida à região interimplantar é melhor distribuída, com participação efetiva do dente na distribuição dessas tensões (MENANI et al., 2011), o que não ocorre quando o contato prematuro existe na extremidade oposta, situação em que maior tensão é transmitida à região cervical do implante da região do 47.

Por fim, ao compararmos a influência da proporção coroa/implante na transferência de tensões aos modelos fotoelásticos, percebe-se que onde foram utilizados implantes curtos, a altura das coroas foi maior que os implantes cerca de 2,62 vezes (Tabela 8), e as tensões transmitidas a esses implantes não foram proporcionalmente maiores quando comparadas aos implantes longos, que por sua vez possuíam coroas com altura cerca de 1,02 vezes o comprimento do implante. Esses resultados são corroborados por Tawil e colaboradores (2006) e Blanes et al. (2007) que em seus estudos, quando a proporção coroa/implante foi maior que 2, os resultados encontrados foram satisfatórios, ou seja, concluíram que a utilização de implantes curtos em regiões com pouca altura óssea promoveu a orientações das forças e distribuição de tensões de maneira bastante favorável, mesmo com alturas maiores das coroas que os comprimentos dos implantes. 
CONCLUSÃO 


\section{CONCLUSÃO}

Considerando os dados obtidos e análises realizadas, dentro dessas condições experimentais é possível concluir que:

- O método fotoelástico utilizado para análise de tensões mostrou correspondência direta entre as análises qualitativas e quantitativas realizadas;

- Mesmo com valores pequenos e aceitáveis clinicamente, os desajustes verticais das próteses promoveram transferência de tensões à região perimplantar;

- Os implantes longos transmitiram mais tensões ao modelo fotoelástico que os implantes curtos;

- O contato oclusal balanceado promoveu distribuição de tensões ao redor todos os implantes e também no dente simulado em resina;

- Os contatos pontuais aplicados transferiram tensões não apenas no implante mais próximo à aplicação de carga, mostrando que a ferulização das próteses promoveu transferência de tensões a outros implantes;

- A proporção coroa/implante maior que 2 não mostrou correspondência com maiores transferências de tensões;

- Implantes curtos mostraram resultados satisfatórios de transferência de tensão à região adjacente aos implantes. 


\section{REFERÊNCIA BIBLIOGRÁFICA ${ }^{1}$}

\footnotetext{
${ }^{1}$ De acordo com o Estilo Vancouver:

US National Library of Medicine. Bibliographic Services Division. International Committee of Medical Journal Editors. Uniform Requeriments for Manuscripts Submitted to Biomedical Journals: sample references. Estados Unidos, 1978 [cited 2006 Oct 25].
} 


\section{REFERÊNCIA BIBLIOGRÁFICA}

Akça K, Fanuscu MI, Caputo AA. Effect of compromised cortical bone on implant load distribution. J Prosthodont. 2008; 17:616-20.

Albrektsson T, Linder L. A method for short- and long-term in vivo study of the bone-implant interface. Clin Orthop Relat Res. 1981; 159:269-73.

Anitua E, Orive G. Short Implants in Maxillae and Mandibles: A Retrospective Study With 1 to 8 Years of Follow-Up. J Periodontol. 2010;81(6):819-826.

Aparício C. A new metod to routinely achieve passive fit of ceramometal prostheses over Branemark osseointegrated implants: a two year report. Int J Periodontics Restorative Dent. 1994; 14:405-419.

Arlin ML. Short dental implants as a treatment option: Results from an observational study in a sigle private practice.Int J Oral Maxillofac Implants. 2006; 21(5):769-76.

Bahat O. Brånemark system implants in the posterior maxilla: clinical study of 660 implants followed for 5 to 12 years. Int J Oral Maxillofac Implants. 2000;15(5):646-53.

Bernabé E, Flores-Mirb C. Dental Morphology and Crowding: A Multivariate Approach. Angle Orthod. 2006; 76:20-25.

Bernardes SR. Análise de tensões em implantes tipo hexágono externo, hexágono interno, cônico interno e peça única utilizando a fotoelasticidade. [dissertação]. Uberlândia: Universidade Federal de Uberlândia, Faculdade de Odontologia; 2004.

Bernardes SR, Araújo CA, Fernandes-Neto AJ, et al. Photoelastic Analysis Stress Patterns from Different Implant-Abutment Interfaces. Int J Oral Maxillofac Implants. 2009; 24(5): 781-789.

Blanes RJ, Bernard JP, Blanes ZM, Belser UC. A 10-year prospective study of ITI dental implants placed in the posterior region. II: Influence of the crown-to-implant ratio and different prosthetic treatment modalities on crystal bone loss. Clin Oral Impl Res. 2007; 18: 707-714.

Bränemark PI. Osseointegration and its experimental background. J Prosthet Dent. 1969; 50(3): 399-410. 
Bruggenkate CM, Asikainen P, Foitzik C, Krekeler G, Sutter F. Short (6-mm) Nonsubmerged Dental Implants: Results of a Multicenter Clinical Trial of 1 to 7 Years. Int J Oral Maxillofac Implants. 1998; 13(6):791-8.

Carr AB, Gerard DA, Larsen PE. The response of bone in primates around unloaded dental implants supporting prostheses with different levels of fit. J Prosthet Dent. 1996; 76(5):500-9.

Cehreli M, Duyck J, Cooman M, Puers R, Naert I. Implant design and interface force transfer: A photoelastic and strain-gauge analysis. Clin Oral Impl Res. 2004;15:249-257.

Clelland NL, Gilat A, McGlumphy EA, et al. A photoelastic and strain gauge analysis of angled abutments for an implant system. Int J Oral Maxillofac Implants. 1993; 4(5):541-8.

Degidi M, Piatelli A, Iezzi G, Carinci F. Immediately loaded short implants: Analysis of a case series of 133 implants. Quintessence Int. 2007; 38(3):193-201.

Friberg B, Jemt T, Lekholm U. Early failures in 4,641 consecutively placed Bränemark dental Implants: A study from stage 1 surgery to the connection of completed prostheses. Int J Oral Maxillofc Implants. 1991; 6(1):142-46.

Fugazzotto PA. Shorter implants in Clinical Practice: Rationale and treatment results. Int J Oral Maxillofac Implants. 2008; 23(3):487-96.

Goené R, Bianchesi C, Hüerzeler M, Del Lupo R, Testori T, Davarpanah M, Jalbout Z. Performance of Short Implants in Partial Restorations: 3-Year Follow-up of Osseotite Implants. Implant Dent. 2005; 14(3):274-280.

Goodacre CJ, Bernal G, Rungcharassaeng K, et al. Clinical complications with implants and implant prostheses. J Prosthet Dent. 2003; 90:121-32.

Grant BTN, Pancko FX, Kraut RA. Outcomes of Placing Short Dental Implants in the Posterior Mandible: A Retrospective Study of 124 Cases. J Oral Maxillofac Surg 2009; 67:713-717.

Guichet DL, Caputo AA, Choi H, Sorensen JA. Passivity of Fit and Marginal Opening in Screw- or Cement-Retained Implant Fixed Partial Denture Designs. Int J Oral Maxillofac Implants. 2000; 15(2):239-246.

Guichet DL, Yoshinobu D, Caputo AA. Effect of splinting and interproximal contact tightness on load transfer by implant restorations. J Prosthet Dent. 2002; 87(5):528-35. 
Haraldson T. A photoelastic study of some biomechanical factors affecting the anchorage of osseointegrated implants in the jaw. Scand J Plast Reconstr Surg Suppl. 1980; 14(3):209-14.

Hohmann A, Wolfram U, Geiger $\mathrm{M}$ et al. Periodontal ligament hydrostatic pressure with areas of root resorption after application of a continuous torque moment. Angle Orthodontist. 2007; 77(4): 653-59.

Jemt T, Lekholm U. Oral implant treatment in posterior partially edentulous jaws: a 5-year follow-up report. Int J Oral Maxillofac Implants. 1993; 8(6):635-40.

Karl M, Taylor TD, Wichmann MG, et al. In vivo stress behavior in cemented an screwretained five unit implant FPDs. J Prosthodont. 2006; 15:20-24.

Mahler DB, Peyton FA. Photoelasticity as a research technique for analyzing stresses in dental structures. J D Res. 1955; 34(6):831-8.

Malo P, Nobre MA, Rangert B. Short Implants Placed One-Stage in Maxillae and Mandibles: A Retrospective Clinical Study with 1 to 9 Years of Follow-Up. Clin Implant Dent Relat Res. 2007; 9(1):15-21.

Menani LR, Tiossi R, Torres EM, Ribeiro RF, Almeida RP. Photoelastic Stress Analysis of Different Designs of Cement-Retained Fixed Partial Dentures on Morse Taper Oral Implants. J Craniofac Surg 2011; 22(2):674-78.

Misch CE, Steignga J, Barboza E, Misch-Dietsh F, Cianciola LJ, Kazor C. Short dental implants in posterior partial edentulism: A multicenter retrospective 6-year case series study. $\mathrm{J}$ Periodontal. 2006; 77(8):1340-47.

Montarou CC, Gaylord TK. Two-Wave-Plate Compensator Method for Single-Point Retardation Measurements. Appl Opt. 2004 Dec;43(36):6580-95.

Nagib NN. New formulas for phase retardance measurements of birefringent plates. Optics \& Laser Technology. 1999 Jun; 31(4):309-13.

Neves FD, Fones D, Bernardes SR, Prado CJ, Fernandes Neto AJ. Short implants - An analysis of longitudinal studies. Int J Oral Maxillofac Implants. 2006; 21(1):86-94.

Nooman M. The use of photoelasticity in a study of cavity preparations. J Dent Child. 1949; 16(4):290-8. 
Otuyemi OD, Noar JH. A comparison of crown size dimensions of the permanent teeth in a Nigerian and a British population. Eur J Orthod. 1996; 18:623-628.

Papavasilliou G, Damposiora P, Bayne SC, et al. Three-dimensional finite element analysis of stress-distribution around single tooth implants as a function of bony support, prosthesis type, and loading during function. J Prosthet Dent. 1996; 76(6):633-40.

Pellizer EP, Tonella BP, Ferraço R, Falcón-Antenucci RM, Carvalho PSP, Alves-Rezende MCR. Photoelastic stress analysis in screwed and cemented implant-supported dentures with external hexagon implants. J Craniofac Surg. 2010; 21(4): 1110-3.

Pierrisnard L, Renouard F, Renault P, Barquins M. Influence of Implant Length and Bicortical Anchorage on Implant Stress Distribution. Clin Implant Dent Relat Res. 2003; 5(4): 254-62.

Rabitz, GK, Berson R, Caputo AA, Franklin RJ, Del Fierro DB. Load-induced stresses in photoelastic primary canines with facial restorations. J Dent Child. 2006; 73(3): 170-74.

Rangert B, Krogh PH, Langer B, et al. Bending overload and implant fracture: a retrospective clinical analysis. Int J Oral Maxillofac Implants. 1995; 10(3): 326-34.

Raviv E, Turcotte A, Harel-Haviv M. Short dental implants in reduced alveolar bone height. Quintessence Int. 2010;41:575-579.

Renouard F, Nisand D. Short Implants in the Severely Resorbed Maxilla: A 2-Year Retrospective Clinical Study. Clin Implant Dent Relat Res. 2005; 7(1):104-10.

Riedy SJ, Lang BR, Lang BE. Fit of implant frameworks fabricated by different techniques. J Prosthet Dent. 1997; 78(6):596-604.

Romeo E, Ghisolfi M, Rozza R, Chiapasco M, Lops D. Short (8-mm) Dental Implants in the Rehabilitation of Partial and Complete Edentulism: A 3- to 14- Year Longitudinal Study. Int J Prosthodont. 2005; 19(6): 586-92.

Sahin SC, Çehreli MC. The significance of passive fit in implant prosthodontics: current status. Implant Dent. 2001; 10:85-89.

Soares CJ, Martins LR, Fonseca RB, et al.. Influence of cavity preparation design on fracture resistance of posterior Leucite-reinforced ceramic restorations. J Prosthet Dent. 2006; 95 (6):421-429. 
Tawil G, Younan R. Clinical Evaluation of Short, Machined-Surface Implants Followed for 12 to 92 Months. Int J Oral Maxillofac Implants. 2003; 18(6):894-901.

Tawil G, Aboujaoude N, Younan R. Influence of Prosthetic parameters on the survival and complication rates of short implants. Int J Oral Maxillofac Implants. 2006; 21(2):275-282.

Tiossi R, Lin L, Rodrigues RCS, Heo YC, Conrad HJ, Mattos MGC, Ribeiro RF, Fok ASL. Digital image correlation analysis of the load transfer by implant-supported restorations. J Biomech. 2011; 44:1008-13.

Torres EM, Barbosa GA, Bernardes SR, Mattos MGC, Ribeiro RF. Correlation between vertical misfits and stresses transmitted to implants from metal frameworks. J Biomech. 2011; 44(9):1735-9.

Watanabe F, Uno I, Hata Y, et al. Analysis of stress distribution in a screw-retained implant prosthesis. Int J Oral Maxillofac Implants. 2000; 15(2):209-18.

Zarb GA, Albrektsson T. Osseointegration: A requiem for the periodontal ligament? [guest editorial]. Int J Periodont Rest Dent. 1991; 11(2):88-91. 
ANEXO 
Quadro 1. Ordens de franja $(\eta)$ medidas em cada um dos pontos, sob a aplicação de cada uma das cargas.

\begin{tabular}{|c|c|c|c|c|c|c|c|c|c|c|c|c|c|c|c|c|}
\hline \multirow[b]{2}{*}{$\begin{array}{l}\text { Pontos de } \\
\text { leitura }\end{array}$} & \multicolumn{4}{|c|}{ Somente a prótese } & \multicolumn{4}{|c|}{ Carga oclusal distribuída } & \multicolumn{4}{|c|}{$\begin{array}{l}\text { Contato Pontual na Mesial } \\
\text { do } 45\end{array}$} & \multicolumn{4}{|c|}{$\begin{array}{l}\text { Contato Pontual na Distal } \\
\text { do } 47\end{array}$} \\
\hline & G1 & G2 & G3 & G4 & G1 & G2 & G3 & G4 & G1 & G2 & G3 & G4 & G1 & G2 & G3 & G4 \\
\hline 1 & 0,81 & 0,26 & 0,35 & 0,32 & 1,18 & 0,70 & 1,45 & 1,89 & 1,18 & 1,00 & 1,60 & 1,35 & 0,77 & 0,00 & 0,00 & 0,37 \\
\hline 2 & 0,48 & 0,31 & 0,05 & 1,33 & 1,96 & 1,78 & 1,35 & 3,24 & 2,69 & 2,09 & 2,24 & 3,18 & 0,50 & 0,78 & 1,00 & 1,57 \\
\hline 3 & 0,29 & 0,26 & 0,31 & 1,56 & 0,69 & 0,74 & 0,47 & 1,77 & 1,00 & 0,46 & 0,52 & 1,80 & 0,40 & 0,56 & 0,48 & 1,82 \\
\hline 4 & 0,38 & 0,77 & 0,59 & 1,55 & 0,00 & 1,29 & 0,60 & 2,00 & 1,21 & 0,44 & 0,00 & 2,00 & 0,48 & 1,00 & 0,40 & 2,86 \\
\hline 5 & 0,85 & 1,28 & 0,73 & 1,69 & 0,19 & 3,08 & 2,78 & 3,28 & 0,54 & 2,17 & 1,69 & 2,70 & 0,47 & 1,48 & 1,47 & 2,22 \\
\hline 6 & 0,55 & 0,09 & 0,74 & 0,00 & 0,35 & 1,00 & 2,47 & 0,41 & 0,29 & 0,60 & 1,31 & 0,30 & 0,49 & 1,00 & 1,00 & 0,06 \\
\hline 7 & 0,71 & 0,39 & 0,70 & 0,33 & 0,74 & 0,53 & 1,66 & 0,64 & 0,44 & 0,38 & 1,00 & 0,39 & 0,46 & 0,00 & 1,20 & 0,39 \\
\hline 8 & 1,39 & 0,22 & 0,76 & 0,58 & 2,46 & 2,63 & 1,82 & 2,82 & 1,55 & 0,18 & 0,69 & 0,73 & 2,64 & 1,37 & 2,93 & 1,8 \\
\hline 9 & 0,54 & 0,37 & 0,54 & 0,21 & 1,40 & 2,69 & 0,82 & 1,39 & 0,80 & 0,20 & 0,80 & 0,23 & 1,75 & 1,32 & 1,45 & 1,35 \\
\hline TOTAL & 6 & 3,95 & 4,77 & 7,57 & 8,97 & 14,44 & 13,42 & 17,44 & 9,7 & 7,52 & 9,85 & 12,68 & 7,96 & 7,51 & 9,93 & 12,44 \\
\hline
\end{tabular}

Quadro 2. Proporção coroa/implante para todos os implantes, em todos os grupos.

\begin{tabular}{|c|c|c|c|c|}
\hline Implantes & G1 & G2 & G3 & G4 \\
\hline $\mathbf{4 5}$ & 1,026 & 1,074 & 2,654 & 1,066 \\
$\mathbf{4 6}$ & 1,022 & 2,696 & 2,644 & 0,993 \\
$\mathbf{4 7}$ & 2,428 & 2,682 & 2,662 & 0,965 \\
\hline
\end{tabular}

